Provided for non-commercial research and education use. Not for reproduction, distribution or commercial use.

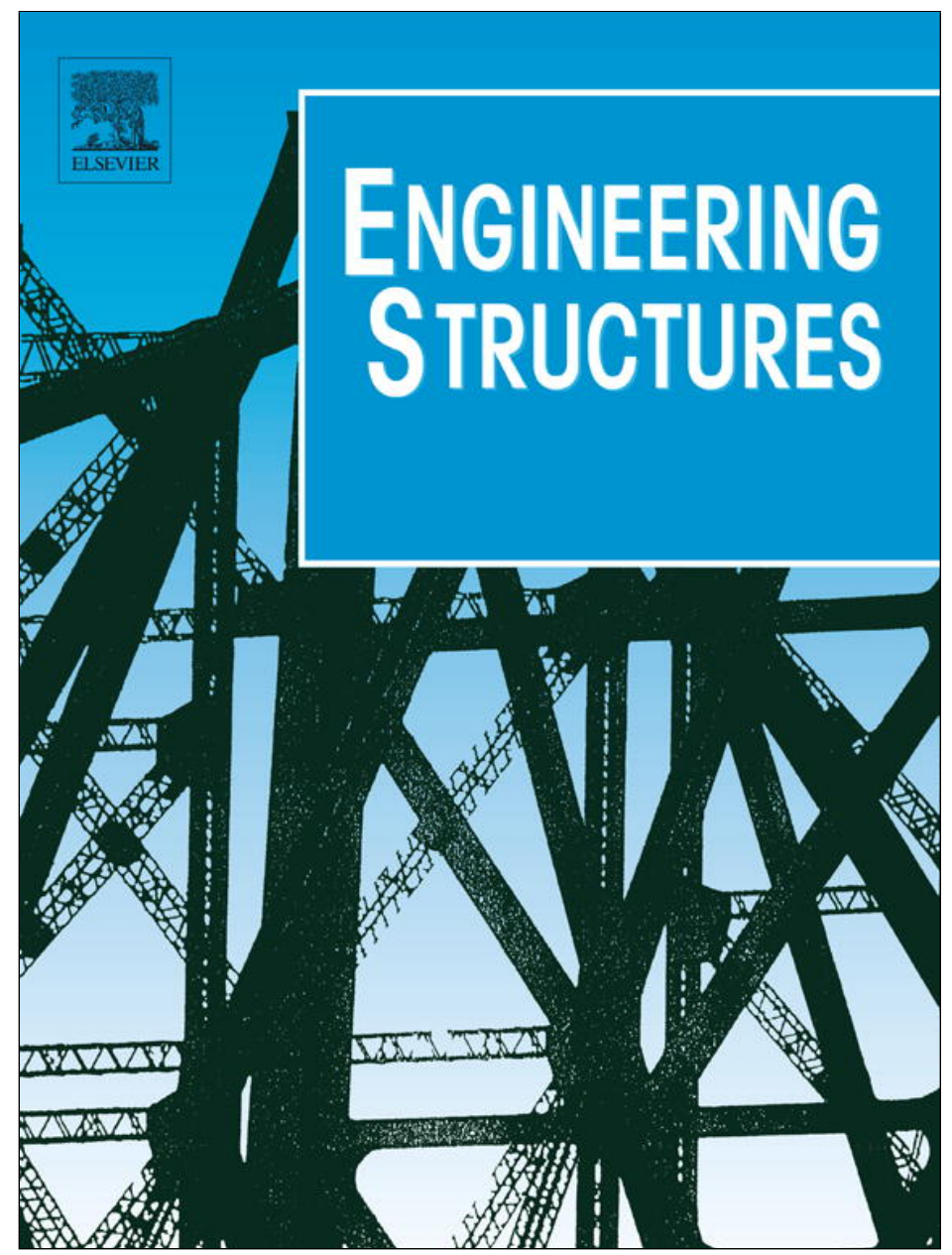

(This is a sample cover image for this issue. The actual cover is not yet available at this time.)

This article appeared in a journal published by Elsevier. The attached copy is furnished to the author for internal non-commercial research and education use, including for instruction at the authors institution and sharing with colleagues.

Other uses, including reproduction and distribution, or selling or licensing copies, or posting to personal, institutional or third party websites are prohibited.

In most cases authors are permitted to post their version of the article (e.g. in Word or Tex form) to their personal website or institutional repository. Authors requiring further information regarding Elsevier's archiving and manuscript policies are encouraged to visit:

http://www.elsevier.com/copyright 


\title{
Peak and residual strengths of brick masonry spandrels
}

\author{
Katrin Beyer* \\ Earthquake Engineering and Structural Dynamics Laboratory (EESD), School of Architecture, Civil and Environmental Engineering (ENAC), École Polytechnique Fédérale de \\ Lausanne (EPFL), Switzerland
}

\section{A R T I C L E I N F O}

\section{Article history:}

Received 24 November 2011

Revised 5 February 2012

Accepted 1 March 2012

\section{Keywords:}

Unreinforced brick masonry

Spandrel elements

Peak strength

Residual strength

Perforated masonry wall

\begin{abstract}
A B S T R A C T
Unreinforced masonry (URM) walls comprise vertical piers and horizontal spandrels, which together form the lateral load resisting system. Whereas past research yielded significant advances in the understanding of the force-deformation characteristics of masonry piers, knowledge of the behaviour of masonry spandrels is lacking. This paper makes a contribution to our understanding of the seismic behaviour of brick masonry spandrel elements by describing typical behaviour modes and analysing the boundary condition of spandrel elements in URM walls. The main part of the paper concerns the development of simple mechanical models for estimating the peak and residual strength of brick masonry spandrels, which are supported either by a timber lintel or a shallow masonry arch. The proposed models are compared against results from experimental tests on four masonry spandrels. It is found that predicted and experimental values agree well.
\end{abstract}

(c) 2012 Elsevier Ltd. All rights reserved.

\section{Introduction}

Past seismic events have shown that unreinforced masonry (URM) buildings are among the most vulnerable structures during earthquakes. In many parts of the world, older URM buildings belong to the cultural heritage and were constructed before seismic design codes were introduced. Improved models of their force-deformation behaviour are required to assess their performance during seismic events and to plan effective retrofit measures. A frequently used method for the seismic analysis of URM buildings is the "equivalent frame approach" (e.g. [1,2]) or the "macro-modelling approach" (e.g. [3-6]). Both modelling approaches require as input the force-deformation characteristics of piers and spandrels (Fig. 1).

The last two decades yielded significant advances in the understanding of the force-deformation characteristics of masonry piers. Experimental test programmes on different pier configurations revealed the typical failure mechanisms of URM piers. Mechanical models for the strength of URM piers associated with these failure mechanisms were developed and are included in today's structural engineering codes. The knowledge of spandrel behaviour is, however, lagging behind our understanding of the piers' behaviour. Although numerical analyses of masonry buildings have shown that spandrel elements can have a significant influence on the global force-deformation behaviour of URM buildings (e.g. [1,2,7,8]), only the FEMA 306 guideline [9] and the Italian seismic design code OPCM $[10,11]$ included strength criteria for masonry spandrels. Of these two, the FEMA 306 equations seem to be the most complete, as they specifically address peak and residual strengths

\footnotetext{
* Tel.: +41 2169362 34; fax: +41216935700.

E-mail address: katrin.beyer@epfl.ch
}

and consider for the peak strength also different types of failure modes. However, they account neither for the redistribution of vertical stresses in the spandrel under lateral loading nor for the contribution of a timber lintel or masonry arch to the resistance of the masonry spandrel.

This paper contributes to efforts to improve structural models for the seismic analysis of URM buildings by proposing new equations for the peak and residual strength of brick masonry spandrels. The equations can be used, for example, in equivalentframe or macro-element models to account for the contribution of the spandrels to the global resistance of the URM building. Only clay brick masonry spandrels in buildings with timber floors are addressed in this paper. Neither the behaviour of stone masonry spandrels nor the spandrel behaviour in URM buildings with reinforced concrete slabs or ring beams is covered here; the latter is the topic of ongoing studies (see [12-14]).

The paper begins with the description of the typical forcedeformation behaviour and failure modes of the spandrel. Next is a discussion of the boundary conditions of the spandrel within an URM wall, namely the vertical stresses reaching from the piers into the spandrel, the axial force applied to the spandrel and the imposed deformations. The main part of the paper is dedicated to the description of mechanical models for the peak and residual strengths of brick masonry spandrels with timber lintels or masonry arches. The proposed models are then applied to four brick masonry spandrels, which were tested experimentally $[15,16]$.

\section{Peak and residual strength}

Experimental evidence has shown that the force-deformation behaviour of brick masonry spandrels is often characterised by a 

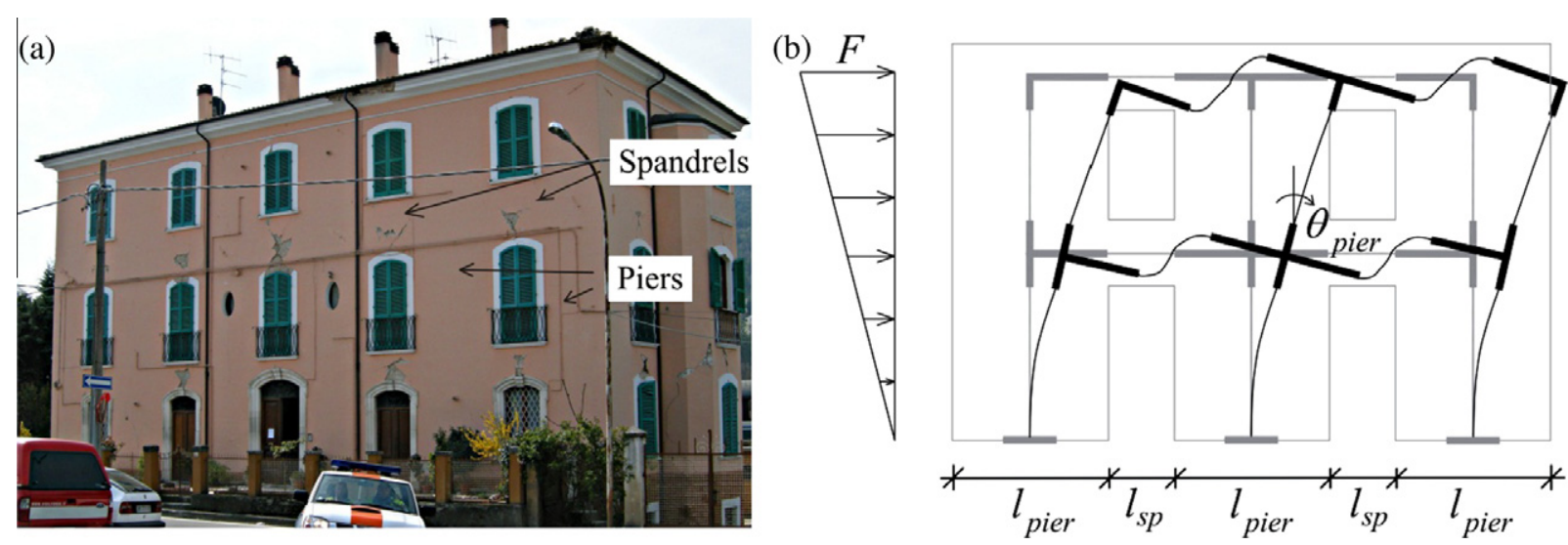

Fig. 1. Old URM building during the L'Aquila earthquake on April 6th, 2009, showing spandrel failure (a). Schematic spandrel deformations within a masonry wall subjected to seismic loading (b).

particular shape of the envelope [15]. Fig. 2 shows an exemplary force-deformation behaviour of a brick masonry spandrel in terms of its axial force $P_{s p}$ and shear force $V_{s p}$ (Fig. 3), which is described hereafter. Once the spandrel cracks, it elongates and elements restraining the spandrel's elongation lead to an increase in axial force in the spandrel. In masonry buildings, the axial elongation of the spandrel is restrained by the adjacent piers and horizontal steel ties, which are often present in ancient masonry buildings. In experimental tests of masonry spandrels, the axial restraint is simulated by horizontal steel rods (e.g. [15]). Both in buildings and spandrel test units, an initial axial force $P_{s p 0}$ in the spandrel can be caused by post-tensioning the horizontal steel rods. The onset of a strong degradation of the spandrel leads to a flattening out of the axial force-deformation relationship and sometimes even to a reduction in the axial force in the spandrel with increasing deformation. During the cyclic loading, the cracks in the spandrel will open and close and the axial force in the spandrel will therefore vary during the earthquake [15].

The shear force in the spandrel increases almost linearly up to $V_{c r}$ when the first cracks form (Fig. 2). Thereafter, the stiffness diminishes until the peak strength $V_{p}$ is reached. Up until the peak strength, the cracks in the spandrel remain rather small. The peak strength is followed by a significant drop in strength and thereafter, the cracks grow significantly in width and number. The strength between the rotations $\theta_{r}$ and $\theta_{u l t}$ is referred to as residual strength, i.e., the strength of the spandrel after the formation of either a flexural or shear crack pattern in the spandrel. The residual strength is closely related to the axial force in the spandrel. Since after cracking the axial force in the spandrel tends to increase, the shear force also increases. If the increase in axial force is large, the residual strength might eventually surpass the peak strength. The shear force-deformation envelope will flatten out and the onset of degradation will eventually lead to failure.

For URM piers the ultimate deformation capacity of the piers is often defined as the deformation for which the shear strength drops to $80 \%$ of $V_{p}$ (e.g., [17,18]). For most spandrel configurations, the drop in strength after attaining the peak shear strength will exceed $20 \% V_{p}$. Hence, if the same definition was applied to the spandrels, the deformation capacity of most spandrels would correspond to $\theta_{p 2}$ (Fig. 2). This might be overly conservative and lead to rather small deformation capacities of the entire URM wall. Many seismic assessment applications might therefore call for considering explicitly the residual shear strength $V_{r}$ of spandrels.

This paper focuses on the peak and residual shear strength of masonry spandrels that are associated with the formation of flexural and shear mechanisms; the shear strength is in the following

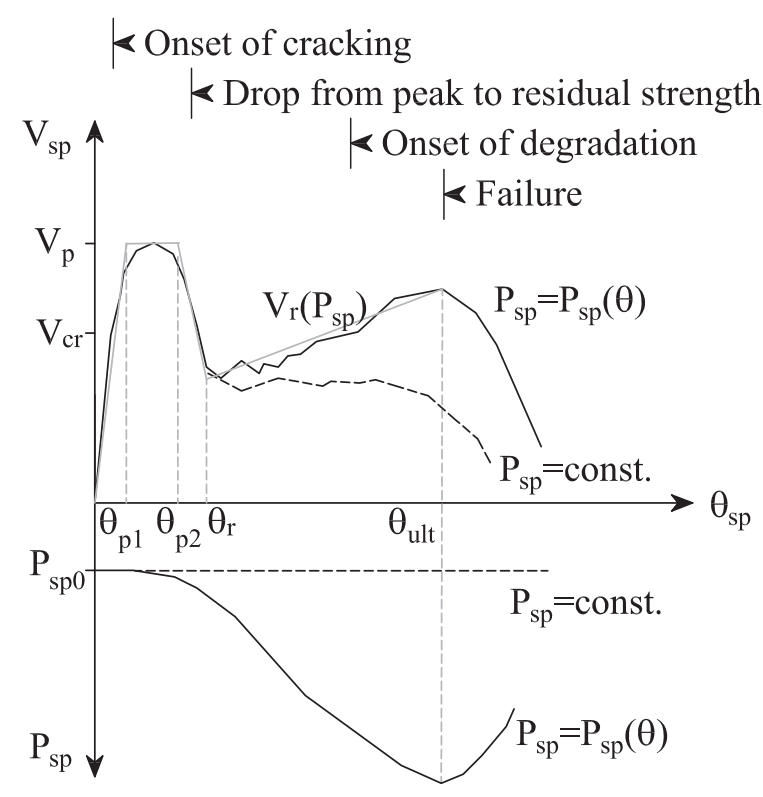

Fig. 2. Schematic dependence of the spandrel's shear strength $V_{s p}$ and axial force $P_{s p}$ on the imposed deformation of the spandrel.

simply referred to as strength of the spandrel. Limit rotations are not defined and are the subject of future studies. However, the proposed strength equations can be used to set-up simplified forcerotation relationships for the spandrel elements:

- A linear elastic relationship up to $V_{p}$ assuming that the initial elastic stiffness can be computed as for piers, i.e., based on homogenous section properties and a stiffness reduction factor of $0.3-0.5$ (e.g. [18]).

- A linear elastic - perfectly plastic relationship with a maximum shear force of $V_{r}$ and an initial stiffness as for the first approach.

The current database is too small to propose reliable estimates of the ultimate rotation. In the absence of better estimates, it is suggested to assume similar deformation limits as for piers. The European seismic design code, Eurocode 8 [19] suggests for shear failure a pier drift limit of $0.4 \%$ and for flexural failure of $0.8 \% \mathrm{H}_{0} /$ $D$ where $H_{0} / D$ is the shear ratio. For spandrels, these limits could be adapted to $0.4 \%$ and $0.8 \% l_{s p} / h_{s p}$, respectively (for the definition of $l_{s p}$ and $h_{s p}$ see Fig. 3a). 

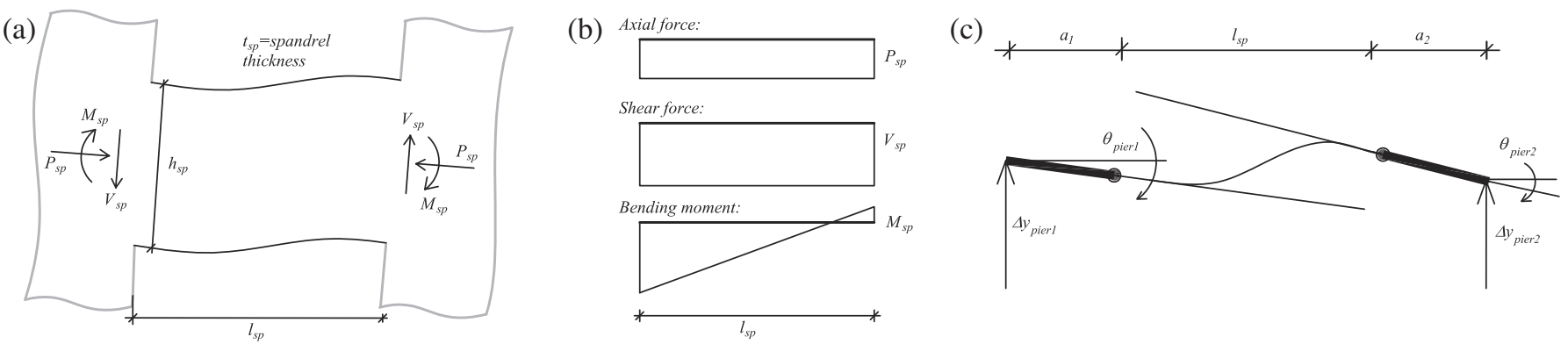

Fig. 3. Geometry of the spandrel (a) internal force diagrams of the spandrel (b) and spandrel deformation as a function of the vertical displacement and chord rotation of the adjacent piers (c) (adopted from [8]).
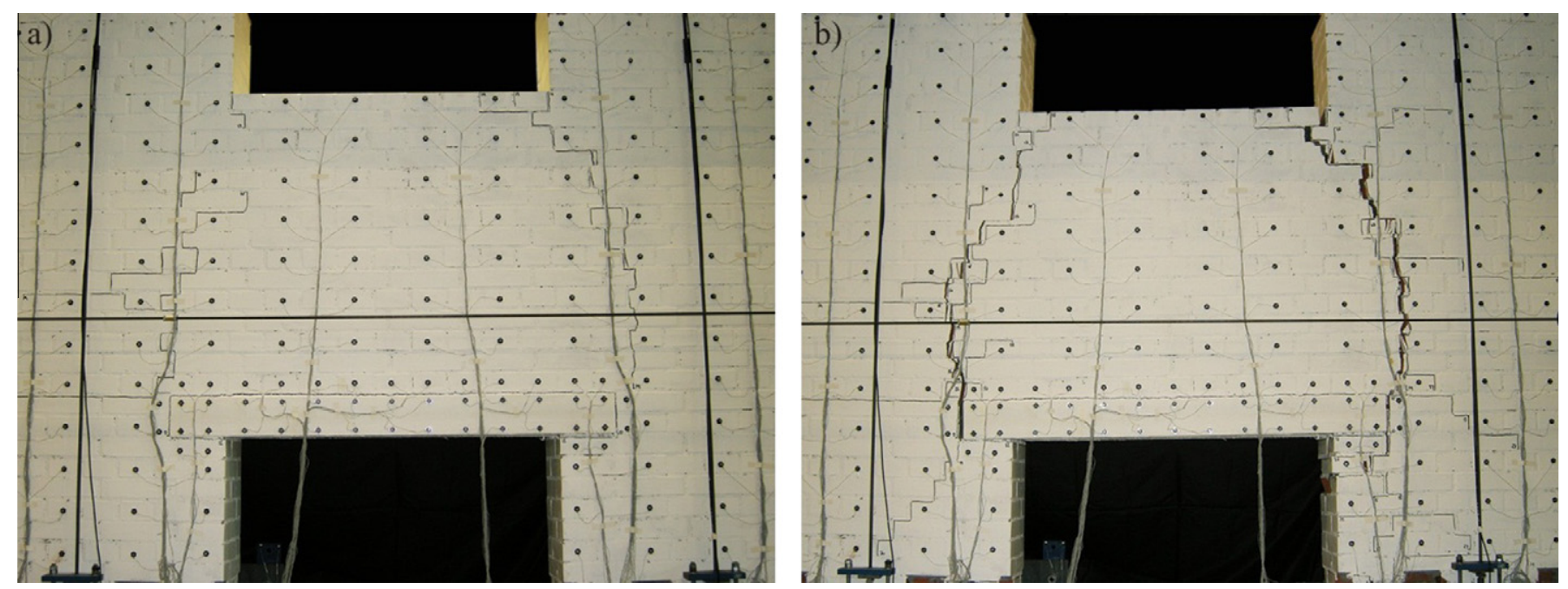

Fig. 4. Flexural cracking of spandrel with timber lintel: Crack pattern for small rotations with flexural cracks that follow the joints (a) and crack pattern for larger rotations with flexural cracks through joints and bricks (b) [16].

\section{Crack pattern and failure modes}

Observations during post-earthquake surveys and experimental tests have shown that for brick masonry spandrels two types of crack patterns can be distinguished, i.e., a flexural and a shear crack pattern [15]. Flexural cracking is associated with the formation of cracks that are approximately vertical. At the onset of cracking, the flexural cracks often pass through head and bedjoints (Fig. 4a), but as the cracks become wider, more and more bricks break and the crack passes mainly through head joints and bricks (Fig. 4b). The resulting flexural mechanism is therefore a rocking mechanism on a rupture plane through head joints and bricks. For spandrels with timber lintels the crack typically reaches around the end of the timber lintel (Fig. 4); in spandrels with masonry arches the first flexural cracks appear typically in the arch itself and then spread into the spandrel (Fig. 5a). For this reason the flexural rupture planes are typically not absolutely planar but are instead curved. The final flexural failure mechanism resembles a rocking mechanism on the rupture plane.

The shear cracking of spandrel elements leads to the characteristic X-type crack pattern (Fig. 5b), which is also known from the shear failure of masonry piers. Shear cracking is common for squat spandrels with large axial forces whereas flexural cracking is typical for slender spandrels or spandrels with small axial forces [15]. In addition to flexural and shear type of failure, mixed failure modes have been observed, where, for example, at the beginning flexural cracks develop but - due to the increase in axial force with increasing deformation - the residual strength is controlled by shear failure. When the cracks are relatively wide, the out-of-plane accelerations may lead to out-of-plane failure of the spandrel. This type of failure is not considered when developing thereafter mechanical strength models since it does not affect the peak and residual strength significantly; it may, however, control the ultimate deformation capacity of the spandrel.

For piers, a third failure mode, i.e., the sliding shear failure, is considered [17]. For spandrels, sliding is not a mechanism that is capable of initiating the cracking of the spandrel because the shear force acts perpendicular to the bed joints. The sliding mechanism can, however, control the residual strength of the spandrel once flexural cracking leads to an approximately vertical rupture plane. However, as outlined above, in most cases the rupture plane will be curved, and hence the sliding failure of spandrels is rather unlikely and will not be considered hereafter.

\section{Boundary conditions of spandrels}

The behaviour of the spandrels in URM walls during seismic loading is largely controlled by the behaviour of the adjacent piers, which define the boundary conditions of the spandrel element. The boundary conditions can be described in terms of the imposed spandrel displacement, the restraint against axial elongation of the spandrel and the vertical stresses that reach from the piers into the spandrel. The following sections discuss these boundary conditions in more detail. 

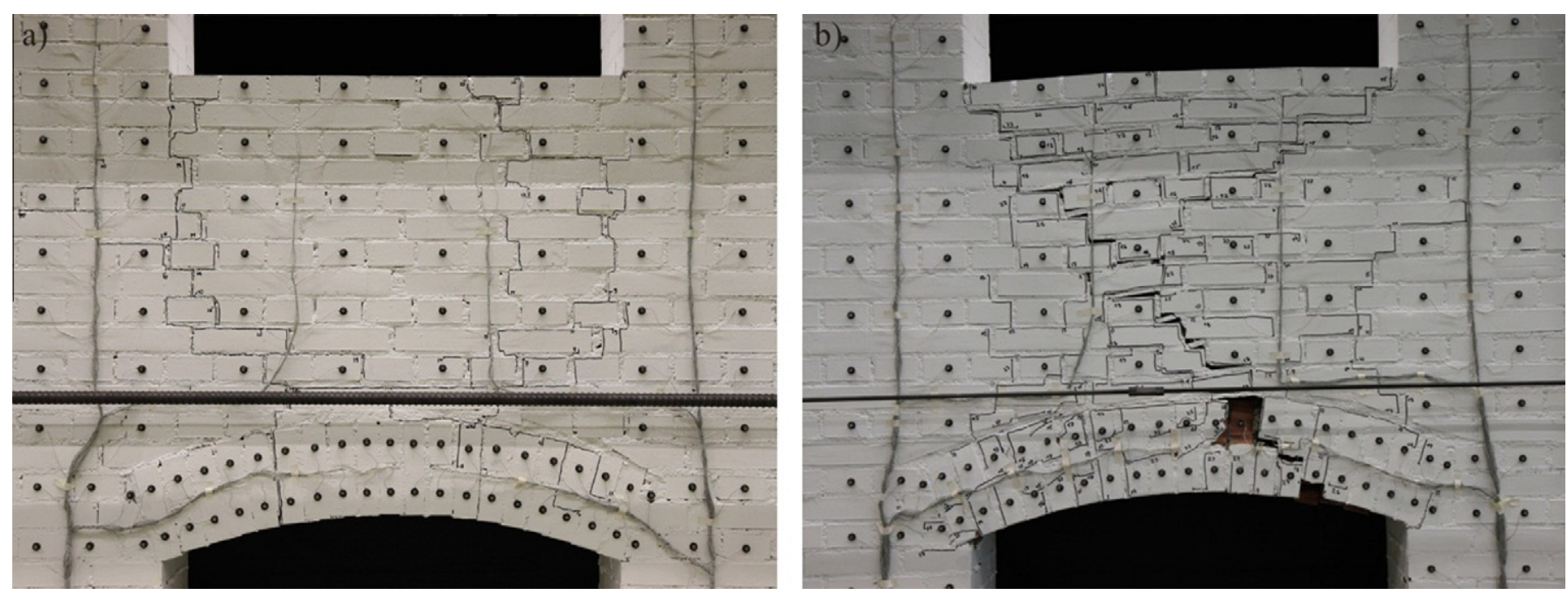

Fig. 5. Flexural (a) and shear (b) cracking of spandrels with masonry arches [16].

\subsection{Relationship between the deformations of piers and spandrels}

During an earthquake the URM building is subjected to lateral displacements, which are in the following expressed as drift $\theta_{\text {pier }}$ of the piers. The deformation demand on the spandrel elements is a function of the deformation of the adjacent piers and the geometry of piers and spandrels (Fig. 2b). A "spandrel displacement" $\Delta_{s p}$ and a "spandrel rotation" $\theta_{s p}$ can be computed as follows [8]:

$\Delta_{s p}=\Delta y_{\text {pier } 1}-\Delta y_{\text {pier } 2}+\theta_{\text {pier } 1}\left(a_{1}+\frac{l_{s p}}{2}\right)+\theta_{\text {pier } 2}\left(a_{2}+\frac{l_{s p}}{2}\right)$

$\theta_{s p}=\frac{\Delta_{s p}}{l_{s p}}$

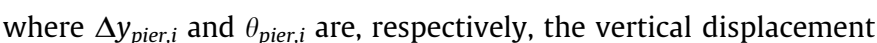
and the chord rotation of the axis of the pier $i$ at the height of the spandrel, $a_{i}$ is the distance between the pier axis and the spandrel face and $l_{s p}$ is the spandrel length (Fig. 3c). In a large masonry wall with regular openings and pier dimensions, the equations for the spandrel deformation simplify to:

$\Delta_{s p}=\theta_{\text {pier }}\left(l_{\text {pier }}+l_{s p}\right)$

$\theta_{s p}=\theta_{\text {pier }} \frac{\left(l_{\text {pier }}+l_{s p}\right)}{l_{s p}}$

where $\theta_{\text {pier }}$ is the average pier rotation at the height of the spandrel and $l_{\text {pier }}$ is the pier length. Eq. (2b) shows that in a regular masonry wall the rotation demand on the spandrels is larger than the rotation demand on the piers.

\subsection{Axial force in the spandrel}

The axial force in the spandrel has a significant effect on the spandrel behaviour. As outlined in Section 2, the axial force $P_{s p}$ varies as a function of the deformation demand on the spandrel. In a building, the axial force in the spandrel can be typically attributed to the restraining effect of horizontal steel ties and adjacent piers. When the spandrels crack, they tend to elongate and are therefore pulling the steel ties and pushing the piers apart. In buildings the axial force in the spandrel will thus increase after the onset of cracking and the spandrel strength after cracking is therefore not a constant value (Fig. 2). In tests on masonry spandrels, the restraint provided by steel ties and piers is typically simulated by horizontal steel ties. Note that in some tests on masonry spandrels (e.g. TUA and TUC in [15]) the axial force applied by these steel ties was kept constant throughout the test (Fig. 2). In other tests (e.g.TUB and TUD in [15]), the steel ties are locked-in and hence the axial force applied to the spandrel is not constant but depends on the stiffness of the steel ties. Both setups constitute a simplification of the boundary conditions in real masonry walls. The second test setup with locked-in steel ties results, however, in boundary conditions that are closer to those in real masonry walls, while the first test setup is typically easier to model numerically.

\subsection{Vertical stresses in the spandrel}

The vertical loads applied to the spandrel are normally limited to the self-weight of the spandrel, which can be neglected for most engineering purposes. At the spandrel ends, however, a stress bulb resulting from the vertical compressive stresses in the piers due to gravity loads reaches into the spandrel. These vertical compressive stresses play an important role when estimating the friction forces that can be transmitted by the bed joints of the spandrel at sections close to the piers $[7,9]$. The vertical stresses in the spandrel diminish from the end section to the midspan of the spandrel. The vertical compressive stresses of the spandrel, $\sigma_{s p}$, can be expressed as a fraction of the mean vertical stress in the piers $\sigma_{\text {pier }}$ :

$\sigma_{s p}=\gamma(x) \cdot \sigma_{\text {pier }}$

where $\gamma(x)$ is a function of the position along the spandrel axis $x$. Fig. 6a shows the vertical stresses in a spandrel with aspect ratio $h_{s p} / l_{s p}=1.25$ for a vertical compressive stress in the pier of $\sigma_{\text {pier }}=1.0 \mathrm{MPa}$. For this analysis, the masonry was modelled as homogenous, elastic material and the models were analysed using the program "Atena" [20]. Fig. 6b shows the results of a small parametric study for spandrels with different aspect ratios. The results are evaluated in terms of the mean vertical stress over the height of the spandrel as well as the vertical stress at the spandrel axis. FEMA 306 [9] and Cattari and Lagomarsino [7] both account for these clamping stresses on the bed joints when computing the flexural resistance of the spandrel. FEMA 306 suggests estimating the mean clamping stress at the end of the spandrel as $\sigma_{s p}=0.5 \sigma_{\text {pier }}$ whereas Cattari and Lagomarsino propose $\sigma_{s p}=0.65 \sigma_{\text {pier }}$. Fig. 6b shows that these fractions correspond approximately to the stress at the spandrel ends.

Under lateral loads and in particular after the onset of cracking, the compressive stress bulb reaching into the spandrel will be 

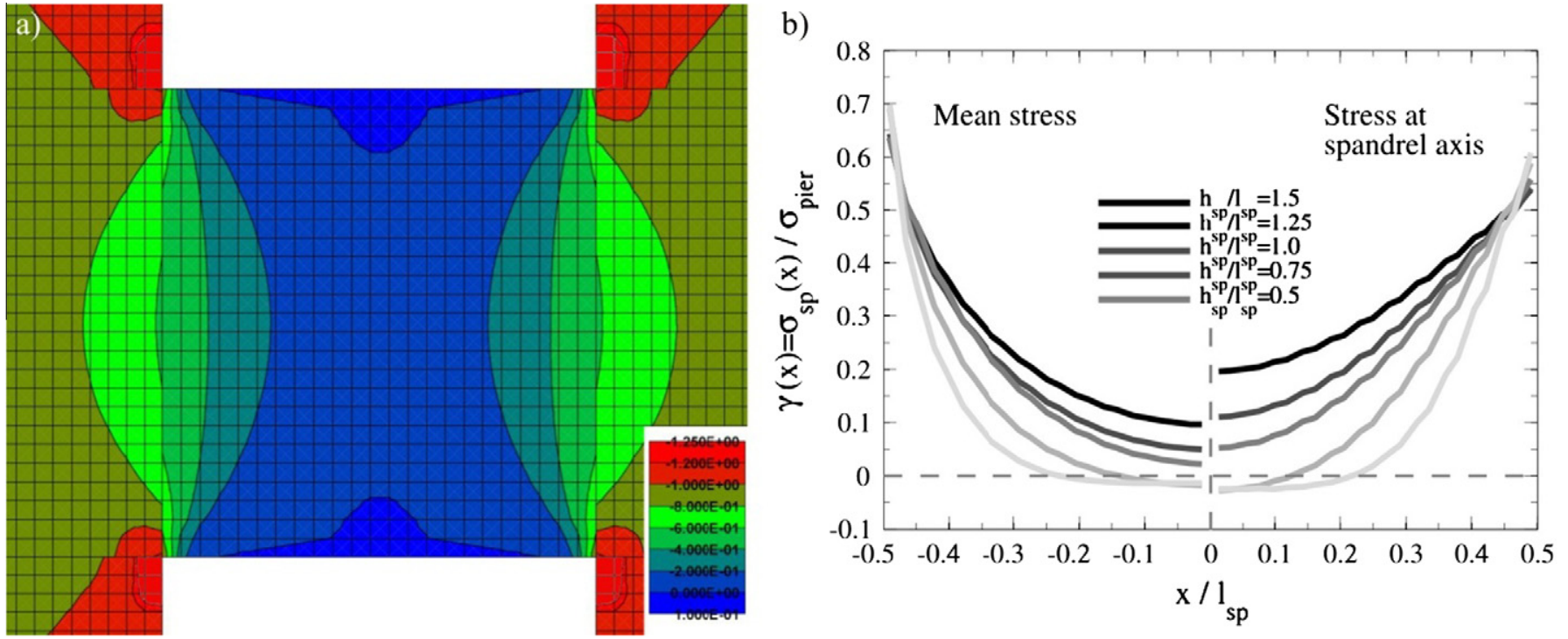

Fig. 6. Vertical stresses in the spandrel due to gravity loads: Vertical stresses in a spandrel with aspect ratio 1.25 (a) and mean vertical stresses and stresses at the element axis for spandrels of different aspect ratios (b).
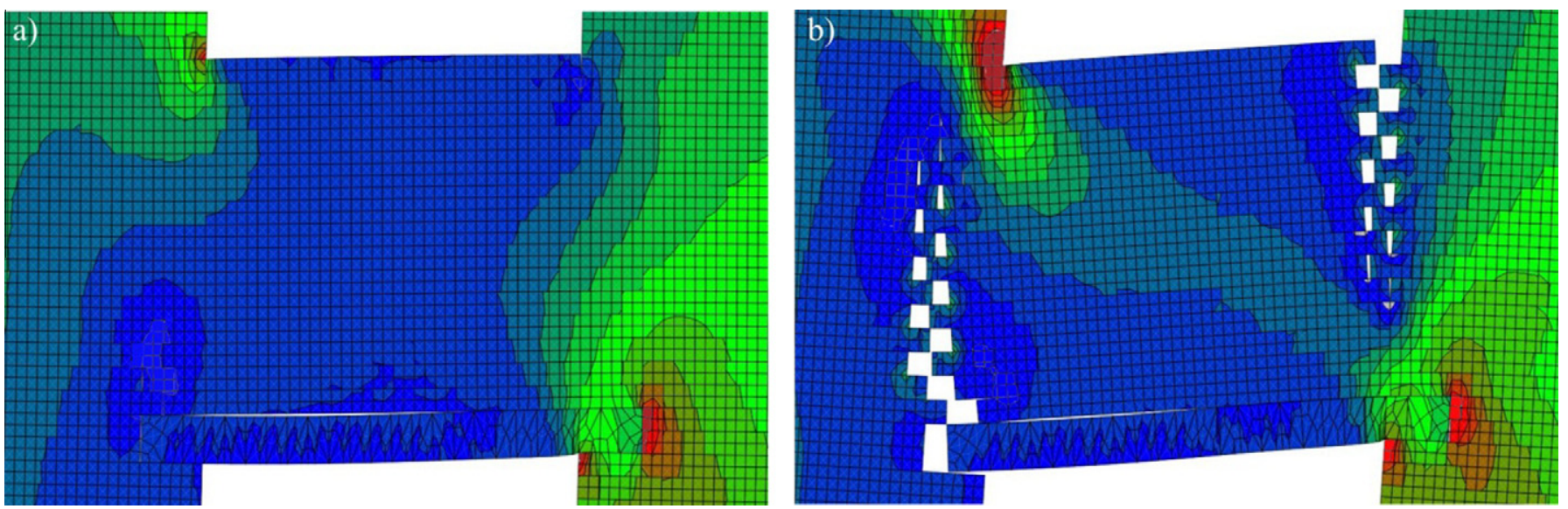

Fig. 7. Vertical stresses in spandrel when the wall is subjected to lateral loading: before the onset of cracking in the spandrel (a) and after the onset of cracking (b).

transformed into a compression strut, which has its origin in the compression strut in the piers subjected to lateral loading and which reaches into the spandrel (Fig. 7). Thus, after the onset of cracking the vertical compressive stresses on the bed joints, which are subjected to sliding displacements and which form the vertical flexural cracks in the spandrel, are rather small.

\section{Strength of brick masonry spandrels}

This section presents mechanical models and equations for estimating the peak and residual strengths of a brick masonry spandrels responding either in a flexural or shear mode. First, the peak and residual strengths of the brick masonry spandrel alone are analysed. Next, the contributions of a timber lintel (Fig. 8a) or a shallow masonry arch (Fig. 8b) to the strength of the spandrel element are discussed. The proposed strength equations are summarised in the last part of this section. For the following calculations, the spandrel is assumed to be subjected to an axial force and a shear force that are constant along the spandrel element axis (Fig. 3c). The mean axial stress in the spandrel is defined as: $p_{s p}=\frac{P_{s p}}{h_{s p} t_{s p}}$

where $P_{s p}$ is the axial force in the spandrel, $h_{s p}$ is the height of the spandrel and $t_{s p}$ is the thickness of the spandrel. It was found that the eccentricity $e_{P s p}$ of the axial force to the spandrel axis has only a minor effect on the spandrel strength and can therefore be neglected (Fig. 8). Moreover, in masonry walls the position of the resultant of the axial stresses might be often unknown and difficult to estimate.

\subsection{Peak strength of the brick masonry spandrel}

The model for estimating the peak strength of masonry spandrels was presented in a simplified form in [15]. For the sake of completeness, the equations are briefly summarised and generalised in terms of the maximum shear stress.

\subsubsection{Flexural cracking}

The flexural peak strength can be estimated from the tensile strength of the head joints and the interlock of the bed joints $[7,9]$. The tensile strength of the head joints is estimated using 


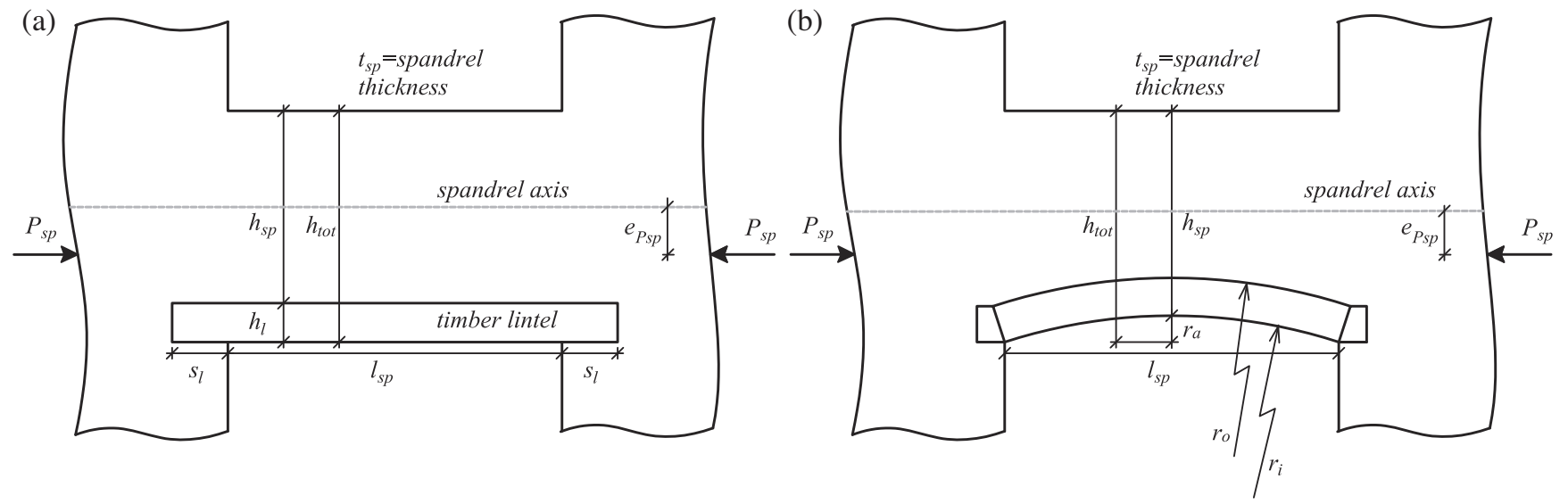

Fig. 8. Geometry of spandrel with timber lintel (a) and masonry arch (b).

the parabolic tension cut-off criterion for mortar joints proposed by Rots and Lourenço [21]. The tensile strength of the head joint is therefore:

$f_{h j}=\frac{c_{p}}{2 \mu_{p}}$

where $\mu_{p}$ and $c_{p}$ are the friction coefficient and cohesion, respectively, which are describing the joint peak strength by means of a Mohr-Coulomb relationship. The shear stress in the bed joints can be transformed into an equivalent tensile strength [7,9]:

$f_{b j}=\left(\mu_{p} \bar{\gamma}_{0.5} \sigma_{\text {pier }}+c_{p}\right) \frac{l_{b}}{2\left(h_{b}+h_{j}\right)}$

where $l_{b} / 2$ is the offset of the stepped flexural crack and $h_{b}+h_{j}$ the average thickness of a brick plus a bed joint (Fig. 9). The stress $\bar{\gamma}_{0.5} \sigma_{\text {pier }}$ is the average vertical stress on a bed joint at the spandrel end, i.e., at the approximate location of the vertical crack (Section 4.3, Fig. 6b). The total equivalent tensile strength of the uncracked masonry spandrel can be computed as the sum of the tensile strength of the head joints and the equivalent tensile strength of the bed joints:

$f_{t}=f_{h j}+f_{b j}$

Assuming a linear stress distribution over the height of the spandrel, the peak moment for which a maximum stress of $f_{t}$ is obtained can be calculated as follows:

$M_{p . f l}=\left(f_{t}+p_{s p}\right) \frac{h_{s p}^{2} t_{s p}}{6}$

If it is assumed that the end moments induced by the seismic loading are equal but opposite, the peak shear force associated with the flexural mechanism of the spandrel can hence be estimated as:

$V_{p . f l}=\frac{2 M_{p . f l}}{l_{s p}}=\left(f_{t}+p_{s p}\right) \frac{h_{s p}^{2} t_{s p}}{3 l_{s p}}$

\subsubsection{Shear cracking}

Assuming a rectangular cross section of the spandrel, the shear stress distribution of the elastic, homogenous spandrel is parabolic over the height. The theoretical shear force initiating shear cracking of a masonry spandrel is therefore:

$V_{c r, s}=\frac{2}{3} \tau_{\max } h_{s p} t_{s p}$

where $\tau_{\max }$ is the maximum shear stress at midheight of the section. It is assumed that the onset of shear cracking occurs in the bed

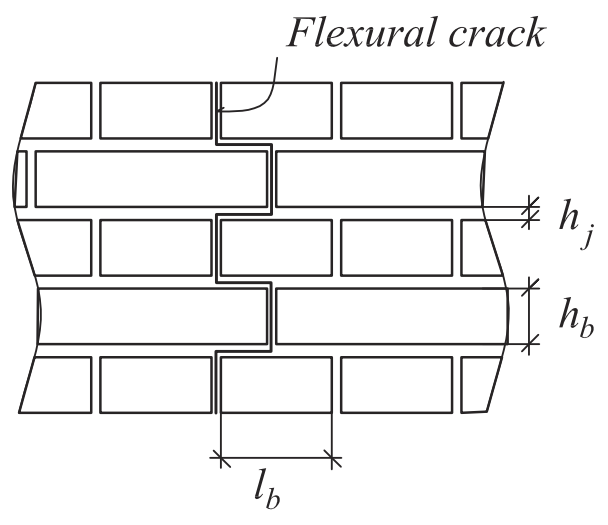

Fig. 9. Geometry of bricks and mortar (adopted from [7]).

joints rather than the head joints since the compressive stresses on the bed joints are typically smaller. The onset of cracking will occur at the section with the smallest shear resistance, i.e., at midspan of the spandrel (Section 4.3). Assuming that shear cracking occurs through the joints, the maximum shear stress at midspan is a function of the bed joint properties and the vertical stress on the bed joint at the spandrel axis $\left(\gamma_{0} \sigma_{\text {pier }}\right)$ :

$\tau_{\max }=c_{p}+\mu_{p} \cdot \gamma_{0} \cdot \sigma_{\text {pier }}$

If the vertical stress on the bed joints is approximately zero, Eq.(11) can be written as:

$V_{c r, s}=\frac{2}{3} c_{p} h_{s p} t_{s p}$

The peak shear strength is associated with the formation of a crack through the head and bed joints over almost the entire height of the spandrel. The peak shear strength is therefore also dependent on the axial force of the spandrel and can be estimated as the peak strength of the head joints:

$V_{p, s 1}=\frac{2}{3}\left(c_{p}+\mu_{p} p_{s p}\right) \cdot h_{s p} t_{s p}$

The interface of the head joints, which are assumed as fully mortared, is assumed to be characterised by the same Mohr-Coulomb law as the interface of the bed joints. If shear failure causes cracking through the bricks, the peak shear strength of the spandrel can be estimated similar to the shear strength of piers [17]: 
(a)

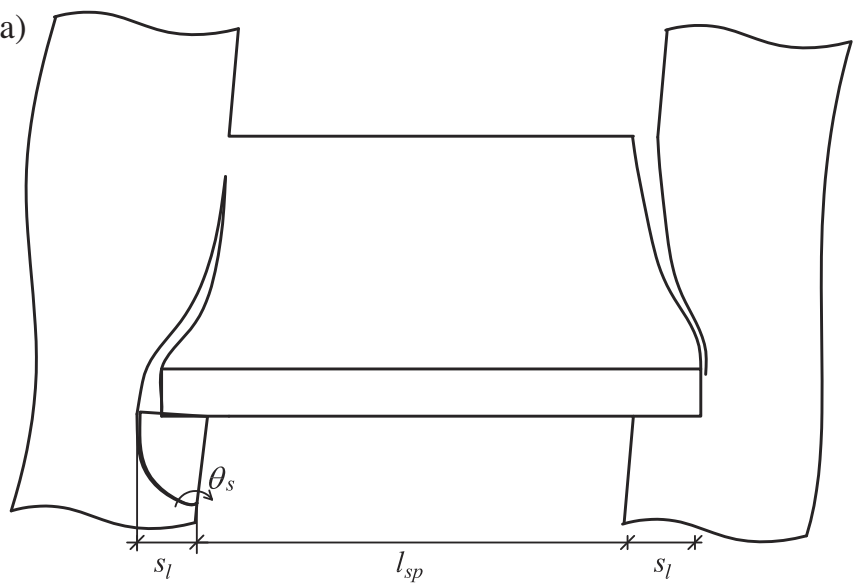

(b)

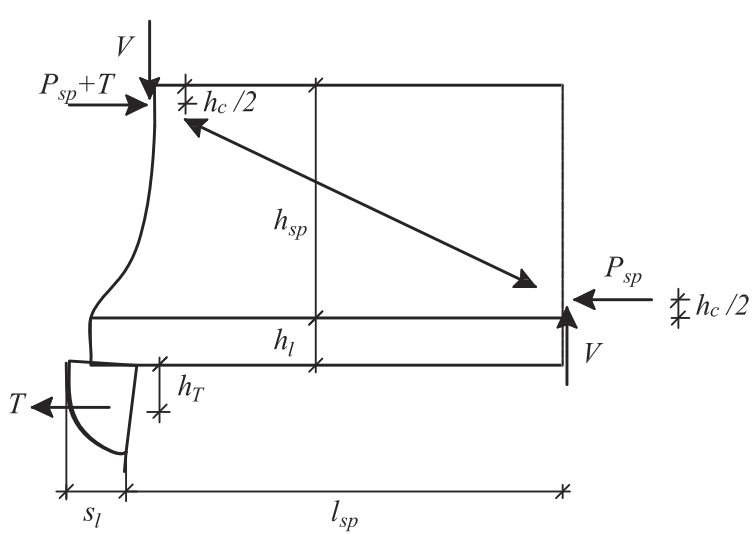

Fig. 10. Flexural mechanism of a spandrel supported by a timber lintel (a) and corresponding free body diagram (b).

$V_{p, s 2}=h_{s p} t_{s p} \frac{f_{b t}^{\prime}}{2.3\left(1+\alpha_{v}\right)} \sqrt{1+\frac{p_{s p}}{f_{b t}^{\prime}}}$

where $f_{b t}^{\prime}$ is the direct tensile strength of the bricks and $\alpha_{v}$ the shear ratio of the spandrel, which is approximately $\alpha_{v}=l_{s p} / 2 h_{s p}$.

\subsection{Residual strength of the brick masonry spandrel}

As for the peak strength, the residual spandrel strength is characterised in terms of the shear and flexural strength of the brick masonry spandrel. The residual shear strength refers to the shear strength after shear cracking and the residual flexural strength to the flexural strength after flexural cracking.

\subsubsection{Residual strength after flexural cracking}

With increasing rotation, the resistance provided by the interlocking bricks tends towards zero for the following reasons: (i) the tensile strength of the head joints and the cohesive strength of the bed joints are lost; (ii) the vertical compressive stress on the bed joints tends towards zero as the compression diagonal develops (Fig. 7b); and (iii) more and more bricks break as a consequence of local stress concentrations when the flexural cracks open (Figs. $4 \mathrm{~b}$ and 10a). The residual strength after flexural cracking is therefore governed by a diagonal compression strut in the masonry spandrel. Assuming a compression zone depth of $h_{c}=P_{s p} / 0.85 f_{h m} t_{s p}$, the associated strength can be estimated as follows $[10,11]$ :

$V_{r . f l}=\frac{P_{s p} h_{s p}}{l_{s p}}\left(1-\frac{p_{s p}}{0.85 f_{h m}}\right)$

where $f_{h m}$ is the strength of the masonry in the horizontal direction, i.e., parallel to the bed joints.

\subsubsection{Residual strength after shear cracking}

It is assumed that the masonry spandrel on its own, i.e., neglecting the contribution of a timber lintel or masonry arch, does not possess a reliable residual strength capacity after shear cracking.

\subsection{Contribution of the timber lintel to peak and residual strength}

This section discusses the effect of the timber lintel on the strength of the spandrel element. The timber lintel is assumed to be supported over a length $s_{l}$ in the adjacent piers (Fig. 8a). The contribution of the timber lintel to the shear and flexural peak strength of the spandrel element is negligible as the timber lintel is very flexible and shallow when compared to the masonry spandrel. However, after flexural or shear cracking the timber lintel can have a significant influence on the residual strength of the spandrel element.

\subsubsection{Contribution of the timber lintel to residual strength after flexural cracking}

If the spandrel is supported by a timber lintel, the timber lintel will slip in and out of the surrounding masonry when the flexural cracks in the masonry spandrelopen and close (Fig. 10a). Fig. 10b yields an idea of the interaction between masonry spandrel and timber lintel as well as of the boundary conditions for the timber lintel. Based on the observations during the tests on spandrels with timber lintels and the failure mechanisms observed from damaged buildings after earthquakes, the residual flexural strength of a masonry spandrel with a timber lintel will be based on the mechanism shown in Fig. 10a.

The movement of the timber induces stresses in the support of the timber lintel. The vertical compressive stresses on the timber lintel support, where the timber lintel is slipping out of the surrounding masonry, are typically rather small (Fig. 10b). However, the cohesive strength of the support can add to the residual flexural strength of the masonry spandrel until the support of the timber lintel fails and a mechanism forms in which the lintel support rotates by $\theta_{S}$ with respect to the surrounding masonry (Fig. 10a). The tension force $T$ can be estimated as the cohesive force transmitted in the bed joints:

$T=c_{p} t_{s p} s_{l}$

where $s_{l}$ is the support length of the timber lintel. The position of the resultant $T$ is difficult to quantify and as a conservative estimate the distance $h_{T}$ of the resultant $T$ to the timber lintel is assumed to be zero. The residual flexural strength after flexural cracking and before failure of the timber lintel support is therefore (Fig. 10b):

$V_{r . f l 0}=\left(P_{s p}\left(h_{s p}-h_{c}\right)+T\left(h_{s p}+h_{l}-\frac{h_{c}}{2}\right)\right) \cdot \frac{1}{l_{s p}}$

where $h_{l}$ is the height of the timber lintel. The compression zone depth $h_{c}$ can be estimated assuming a constant compressive stress of $0.85 f_{h m}$ over the height of the compression zone:

$h_{c}=\frac{P_{s p}+\frac{T}{2}}{0.85 f_{h m} t_{s p}}$

The compression diagonal is assumed to lie entirely in the masonry spandrel and does not pass into the timber lintel since the masonry spandrel is much stiffer than the timber lintel (Eq. (17), Fig. 10b). The tension force $T$ acts as long as the support of the timber lintel 
(a)

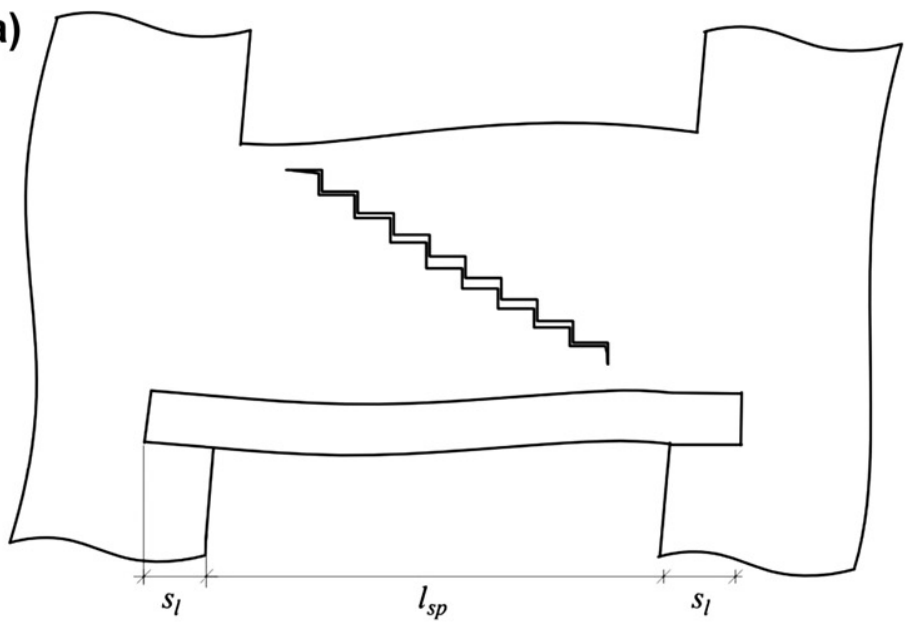

(b)

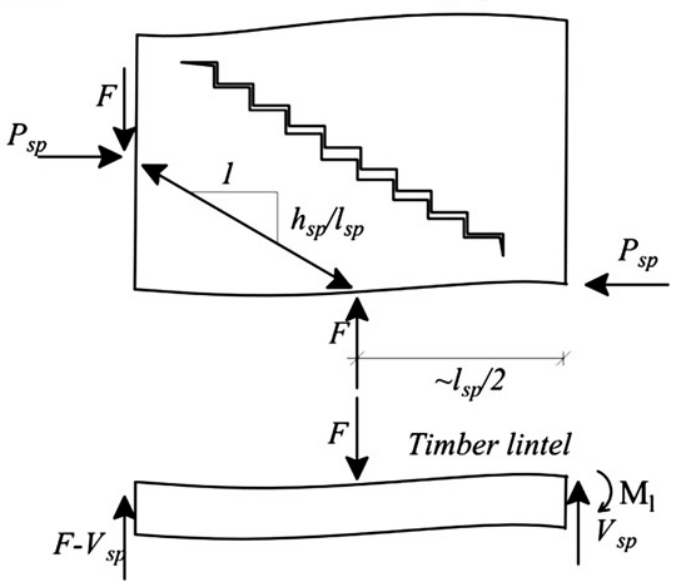

Fig. 11. Shear mechanism of a spandrel supported by a timber lintel (a) and corresponding free body diagram (b).

has not yet failed, i.e., for $\theta_{S} \sim 0$. After failure of the support, the tension force $T$ tends towards zero. The capacity is then equal to the residual flexural strength of a masonry spandrel without timber lintel (Eq. (15)).

\subsubsection{Contribution of the timber lintel to residual strength after shear cracking}

After shear cracking the compression strut can no longer follow the diagonal of the spandrel but has to flow around the disturbed zone through which the diagonal cracks pass (Fig. 11a). The interaction of masonry spandrel and timber lintel after shear cracking of the masonry is rather complex. It is approximated by a very simple truss model, which should lead to conservative estimates of the residual shear strength.

The masonry below the diagonal crack is assumed to remain largely intact and can therefore transfer compressive stresses. It is further postulated that the inclination of the compression diagonal in the masonry spandrel remains the same as before the shear cracking and that the compression diagonal touches the timber lintel at midspan (Fig. 11b). The exact position will depend on many factors, such as whether there is a single diagonal crack or whether several cracks are forming a larger disturbed zone. The timber lintel is considered as a beam, which is simply supported at one end, fixed at the other and loaded by a point load at midspan. Based on these assumptions, the shear force after shear cracking can be computed as:

$V_{r, s}=\frac{11}{16} P_{s p} \frac{h_{s p}}{l_{s p}}$

This shear force is limited by the capacity of the timber lintel $V_{\text {timber }}$.

\subsection{Contribution of the masonry arch to peak and residual strengths}

Contrary to the timber lintel, the masonry arch tends to be stiff and strong and often attracts forces even before the spandrel is cracked. The shear strength carried by the masonry arch is largely dependent on the geometry of the arch (Fig. 8b), i.e., on the arch rise $r_{a}$, the spandrel length $l_{s p}$ and the thickness of the arch $r_{o}-r_{i}$. A number of studies on the behaviour of masonry arches subjected to support deformations have been conducted (e.g., [22,23]). However, studies on the complex interaction of masonry spandrel and masonry arch are lacking. As simple limiting cases, the arch can be neglected or it can be considered as an additional structural element parallel to the spandrel.
The following is a simplified approach for a shallow arch assuming that the arch acts independent of the masonry spandrel between an extrados and an intrados hinge. An arch is considered as shallow if the half angle of embrace $\beta$ satisfies the following equation:

$\cos \beta=\frac{r_{i}-r_{a}}{r_{i}} \geqslant \frac{r_{i}}{r_{o}}$

The dimensions $r_{i}, r_{o}$ and $r_{a}$ are defined in Fig. 8b. If the arch is stiff when compared to the spandrel, the arch tends to separate from the masonry spandrel (Fig. 12a). Support deformations require the immediate formation of plastic hinges if the bricks are considered as rigid $[22,23]$. The strength of the masonry arch for a given axial force is limited by a compression strut tangential to the inner edge of the arch. For a shallow arch, the compression strut is assumed as tangential at one end of the arch. Assuming that the entire axial spandrel force $P_{s p}$ flows through the arch, the shear strength carried by the arch can be estimated as (Fig. 12):

$V_{\text {arch }}=P_{s p} \tan \beta$

$\tan \beta=\frac{l_{s p}}{2\left(r_{i}-r_{a}\right)}$

The approximate position where the extrados plastic hinge will form can be computed from the following set of equations:

$h_{c}=\frac{P_{s p}}{\cos \beta \cdot t_{s p} \cdot 0.85 f_{h m}}$

$x_{\text {hinge }} \cong \sqrt{r_{o}^{2}-\left(r_{i}+h_{c} / 2\right)^{2}} \cdot \cos \beta$

\subsubsection{Contribution of the masonry arch to peak strength}

If the strength of the masonry arch is calculated according to Eq. (21), the strength of the masonry spandrel associated with flexural and shear cracking should be computed for a zero axial force in the spandrel. The total peak strength is then approximately the peak strength of the masonry spandrel plus the strength of the masonry arch:

$V_{p . f l}=f_{t} \frac{h_{s p}^{2} t_{s p}}{3 l_{s p}}+V_{\text {arch }}$

The peak shear strengths associated with cracks through joints and bricks, respectively, can be estimated as: 
(a)

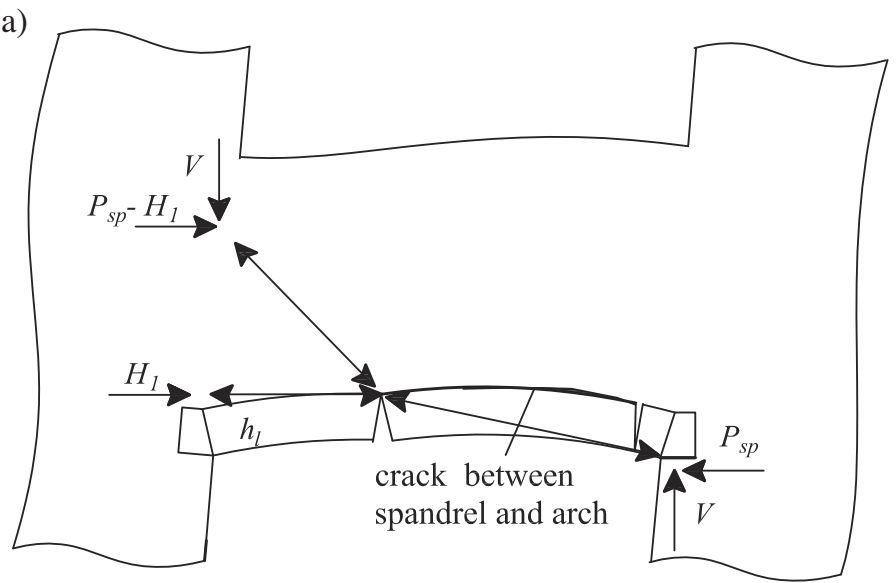

(b)

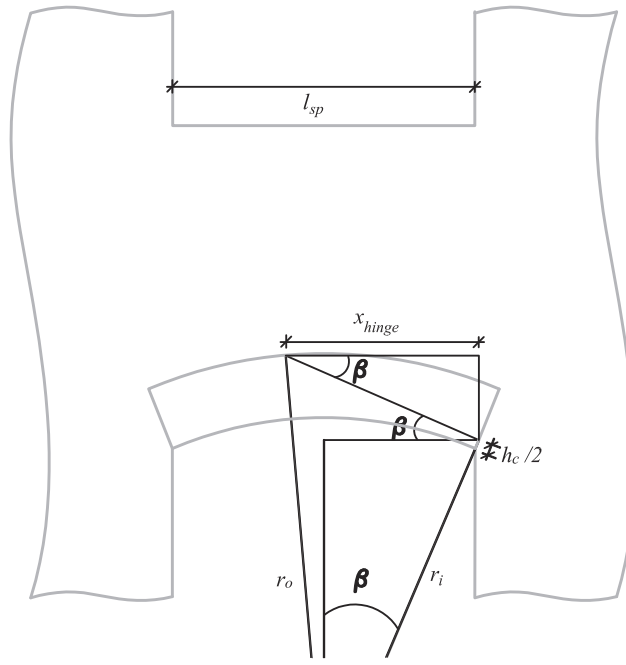

Fig. 12. Arch mechanism: Assumed mechanism and strut model for uncracked spandrel (a) and geometry of strut in arch (b).

(a)

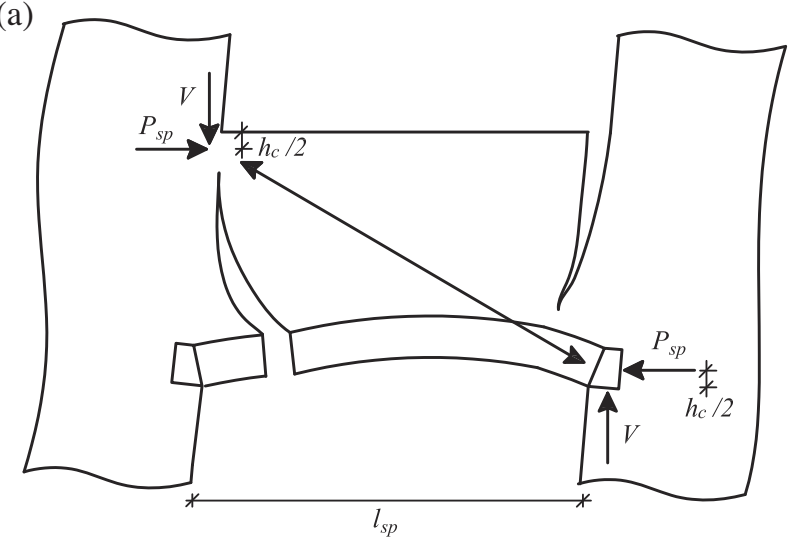

(b)

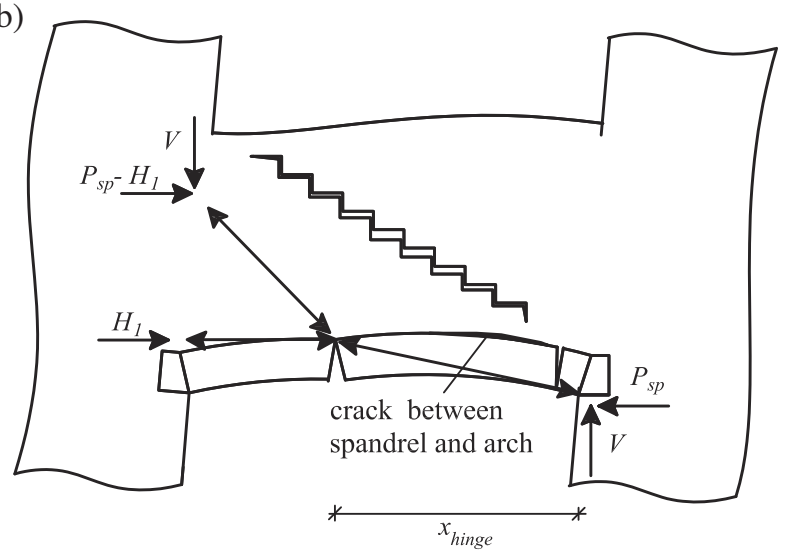

Fig. 13. Spandrel with shallow arch: Assumed load transfer mechanisms after flexural (a) and shear (b) cracking.

$V_{p, s 1}=\frac{2}{3} c_{p} h_{s p} t_{s p}+V_{a r c h}$

$V_{p, s 2}=h_{s p} t_{s p} \frac{f_{b t}^{\prime}}{2.3\left(1+\alpha_{v}\right)}+V_{a r c h}$

5.4.2. Contribution of the masonry arch to residual strength

The residual flexural strength mechanism is similar to that of the masonry spandrel alone (Eq. (15)), but the masonry arch has the effect of increasing the effective height of the spandrel (Fig. 13a):

$V_{r, f l}=\frac{P_{s p} h_{t o t}}{l_{s p}}\left(1-\frac{p_{s p}}{0.85 f_{h m}}\right)$

The residual strength of the masonry spandrel itself is assumed negligible after shear cracking. However, as for the spandrel element with a timber lintel, the masonry below the shear crack is assumed to be capable of transferring compressive stresses. The arch mechanism can therefore still be activated and the residual shear strength is hence equal to the shear strength of the arch (Fig. 13b):

$V_{r, s}=V_{\text {arch }}$

\subsection{Summary of equations for peak and flexural strength}

Tables 1 and 2 summarise the proposed equations for estimating the peak and residual strength of masonry spandrels with timber lintels and shallow arches, respectively. Note that the equations were derived for the purpose of estimating the strengths of spandrels responding either in a flexural mode or a shear mode. Strictly speaking, the equations do therefore not allow assessing mixed mode failures, such as, for example, a spandrel behaviour where flexural cracking is followed by shear cracking and shear failure. Note further that the equations do only reflect the behaviour of the spandrel before the onset of material degradation.

\section{Comparison with experimental results}

This section applies the previously described models for the peak and residual strengths of masonry spandrels to four solid clay brick spandrel elements that were tested experimentally and compares the predicted strength capacities with the experimentally determined values.

\subsection{Quasi-static cyclic tests}

Four test units representing solid clay brick masonry spandrel elements and the adjacent piers were tested under quasi-static cyclic loading $[15,16]$. The masonry spandrels included either a timber lintel or a shallow masonry arch (Table 3 ). The test setup imposed a drift on the two piers, which defined the deformation demand on the spandrel (Fig. 14). The axial elongation of the 
Table 1

Summary of strength equations for masonry spandrels with timber lintels.

\begin{tabular}{ll}
\hline Flexural mode & Shear mode \\
\hline Onset of cracking: Not considered & Onset of cracking (Eq. (12)): \\
& $V_{c r, s}=\frac{2}{3} c_{p} h_{s p} t_{s p}$ \\
& Assumption: The stress on the bed joints at midspan is approximately zero. \\
Peak strength (Eq (9)): & Peak strength (cracks through joints, Eq. (13)): \\
$V_{p, f l}=\left(f_{t}+p_{s p}\right) \frac{h_{s p}^{2} t_{s p}}{3 l_{s p}}$ & $V_{p, s 1}=\frac{2}{3}\left(c_{p}+\mu_{p} p_{s p}\right) \cdot h_{s p} t_{s p}$ \\
with $f_{t}=\left(\mu_{p} \bar{\gamma}_{0.5} \sigma_{p i e r}+c_{p}\right) \frac{l_{b}}{2\left(h_{b}+h_{j}\right)}+\frac{c_{p}}{2 \mu_{p}}$ & Peak strength (cracks through bricks, Eq. (14)): \\
& $V_{p, s 2}=h_{s p} t_{s p} \frac{f_{b t}^{\prime}}{2.3\left(1+\alpha_{v}\right)} \sqrt{1+\frac{p_{s p}}{f_{b t}^{\prime}}}$ \\
Residual strength before failure of lintel support (Eqs. (16)-(18)): & Residual strength (Eq. (19))): \\
$V_{r . f l 0}=\left(P_{s p}\left(h_{s p}-h_{c}\right)+T\left(h_{s p}+h_{l}-\frac{h_{c}}{2}\right)\right) \cdot \frac{1}{l_{s p}}$ & $V=$ min $\left(\frac{11}{16} P_{s p} \frac{h_{s p}}{l_{s p}} ; V_{t i m b e r}\right)$ \\
with $T=c_{p} t_{s p} s_{l}$ and $h_{c}=\frac{P_{s p}+\frac{T}{2}}{0.85 f_{h m} t_{s p}}$ & \\
Residual strength after failure of lintel support (Eq. (15)): & \\
$V_{r, f l}=\frac{P_{s s} h_{s p}}{l_{s p}}\left(1-\frac{p_{s p}}{0.85 f_{h m}}\right)$ & \\
\hline
\end{tabular}

Table 2

Summary of strength equations for masonry spandrels with stiff, shallow masonry arches.

\begin{tabular}{ll}
\hline Flexural mode & Shear mode \\
\hline Onset of cracking: First cracks in the arch for very small rotations (Eqs. (21) and (22)): & \\
$V_{c r}=V_{\text {arch }}=P_{s p} \tan \beta$ with $\tan \beta=\frac{l_{s p}}{2\left(r_{i}-r_{a}\right)}$ & Peak strength (cracks through joints, Eq. (25)): \\
Peak strength (Eqs. (9) and (10)): & $V_{p, s 1}=\frac{2}{3} c_{p} h_{s p} t_{s p}+V_{\text {arch }}$ \\
$V_{p, f l}=f_{t} \frac{h_{s t_{s p}}^{2} t_{s p}}{3 l_{s p}}+V_{\text {arch }}$ & Peak strength (cracks through bricks, Eq. (26)): \\
with & $V_{p, s 2}=h_{s p} t_{s p} \frac{f_{b t}}{2.3\left(1+\alpha_{v}\right)}+V_{\text {arch }}$ \\
$f_{t}=\left(\mu_{p} \bar{\gamma}_{0.5} \sigma_{p}+c_{p}\right) \frac{l_{b}}{2\left(h_{b}+h_{j}\right)}+\frac{c_{p}}{2 \mu_{p}}$ & Residual strength (Eq. $(28)):$ \\
Residual strength $($ Eq. $(15)):$ & $V_{r, s}=V_{\text {arch }}$ \\
$V_{r, f l}=\frac{P_{s p} h_{t o t}}{l_{s p}}\left(1-\frac{p_{s p}}{0.85 f_{h d}}\right)$ & \\
\hline
\end{tabular}

spandrel was restrained by horizontal tie rods. For two tests (TUA and TUC), the axial force in the spandrel was kept constant over the duration of the tests and hence independent of the imposed drift. For the other two test units (TUB and TUD), the axial force in the spandrel depended on the axial elongation of the spandrel and the stiffness and strength of the tie rods. For this purpose, the tension in the horizontal tie rods was not controlled by hollow core jacks but the rods were locked-in at the beginning of the test and hence the axial force in the spandrel depended on the axial elongation of the spandrel and the stiffness of the rods.

The quasi-static cyclic tests were accompanied by material tests on mortar, brick and masonry, which are also documented in $[15,16]$. Only those material properties are summarised in Table 3 , which are required for the mechanical models presented in Section 5. Note that TUA and TUB as well as TUC and TUD were constructed pairwise at the same time. For each construction phase only one set of compression tests and shear triplets was constructed and tested; for this reason the masonry strength of TUA/ TUB and TUC/TUD are assumed to be equal. For determining the peak strength, the most important property is the Mohr-Coulomb relationship describing the maximum strength $\tau_{\max }$ of the mortar joints by the friction coefficient $\mu_{p}$ and the cohesion $c_{p}$. The tensile strength of the head joints is estimated on the basis of $c_{p}$ according to Eq. (5). The tensile strength $f_{t b}$ of the bricks was obtained from 3point bending tests on prisms. For calculating the shear strength according to Eq. (14), an estimate of the direct tensile strength $f_{t b}^{\prime}$ required. It is assumed that the direct tensile strength $f_{t b}^{\prime}$ can be estimated by calculating two thirds of $f_{t b}$. The horizontal strength $f_{h m}$ of the masonry was not determined experimentally. As a first approximation, the $f_{h m}$ is taken as the strength of masonry prisms $f_{c m}$ constructed as a stack of seven bricks loaded in the vertical direction. Note that compression failure of the spandrel is not considered by the models in Section 5 . The horizontal compressive strength is only used to determine the depth of the compression zone $h_{c}$; the spandrel strength is therefore not very sensitive to the assumed value of $f_{h m}$.

\subsection{Comparison of experimental and predicted strength values}

The following two sections compare the predicted strength values with the experimentally obtained values for the spandrels with timber lintels (TUA and TUB) and for the spandrels with shallow masonry arches (TUC and TUD). To enable a more detailed discussion, the following sections also comprise a brief description of the cracking and failure modes; for a more detailed description the reader is referred to $[15,16]$. The strength of masonry spandrels is dependent on the axial force in the spandrel. For the comparison of predicted and experimentally obtained strength values, the recorded axial force is used. The axial force in the spandrel was measured by load cells in the horizontal tie rods.

\subsubsection{Masonry spandrels with timber lintels}

Fig. 15 shows for TUA the comparison of the predicted to the experimentally determined strength values. As test result, only the envelope of the cyclic force-deformation curve is plotted; the envelope of the positive loading direction is plotted as a solid line and the envelope of the negative loading direction as a dashed line. The plot includes both the shear force and the axial force obtained from the test. The forces are plotted against the average pier rotation $\theta_{\text {pier }}$ at the height of the spandrel (Section 4.1). The pier rotation was computed from optical measurements of the pier rotations at the height of the spandrel; the pier rotation therefore excludes the deformation of the piers or the lever beams which are included if the rotation demand is computed from the LVDTs underneath the lever beams [15]. The graph also includes by 
Table 3

Loading scheme, spandrel type and details of the axial force application for the four test units (after [15]).

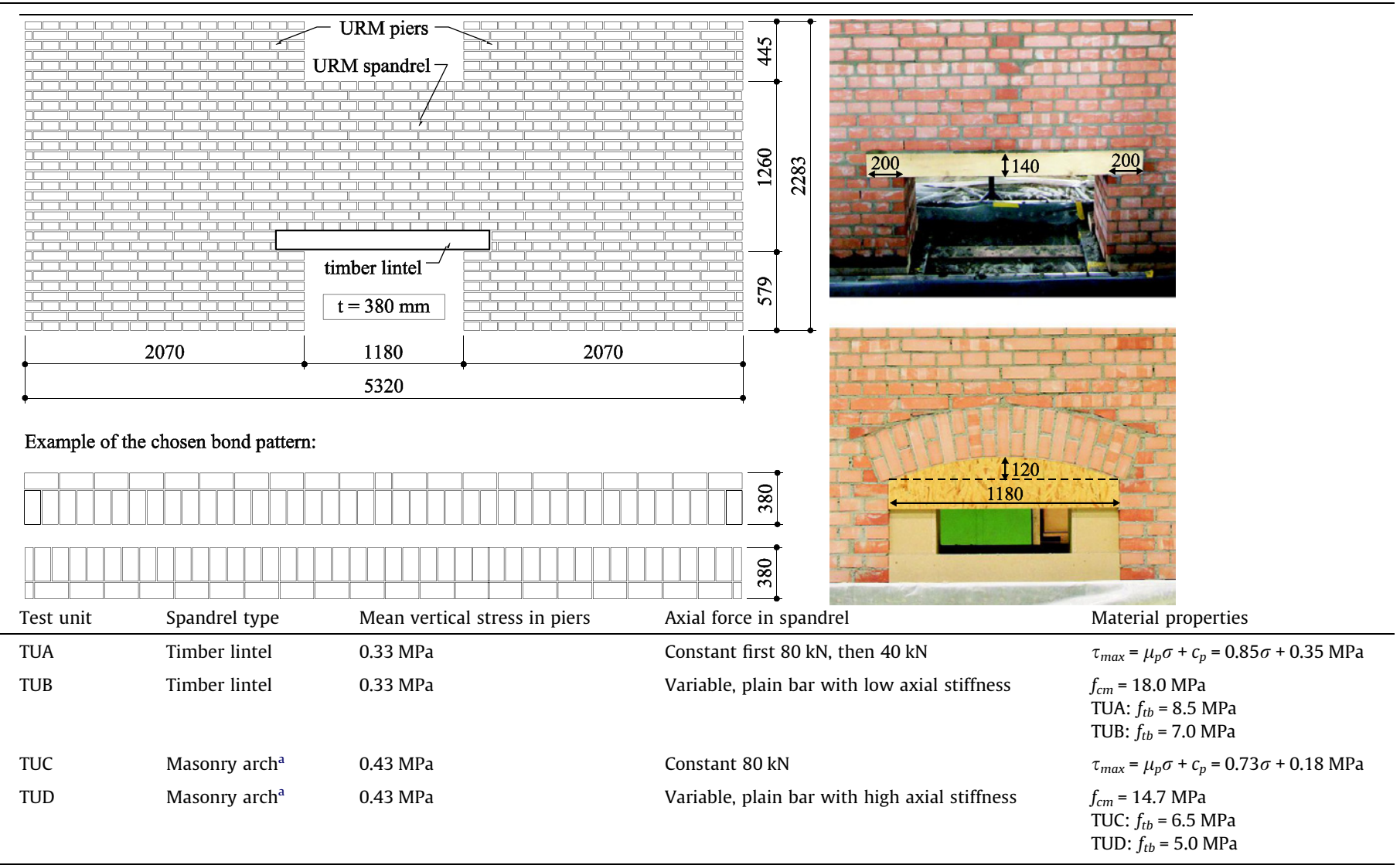

${ }^{\mathrm{a}}$ Geometry of masonry arch: $r_{i}=1505 \mathrm{~mm}, r_{o}=1755 \mathrm{~mm}, r_{a}=120 \mathrm{~mm}$ (Fig. $8 \mathrm{~b}$ ).

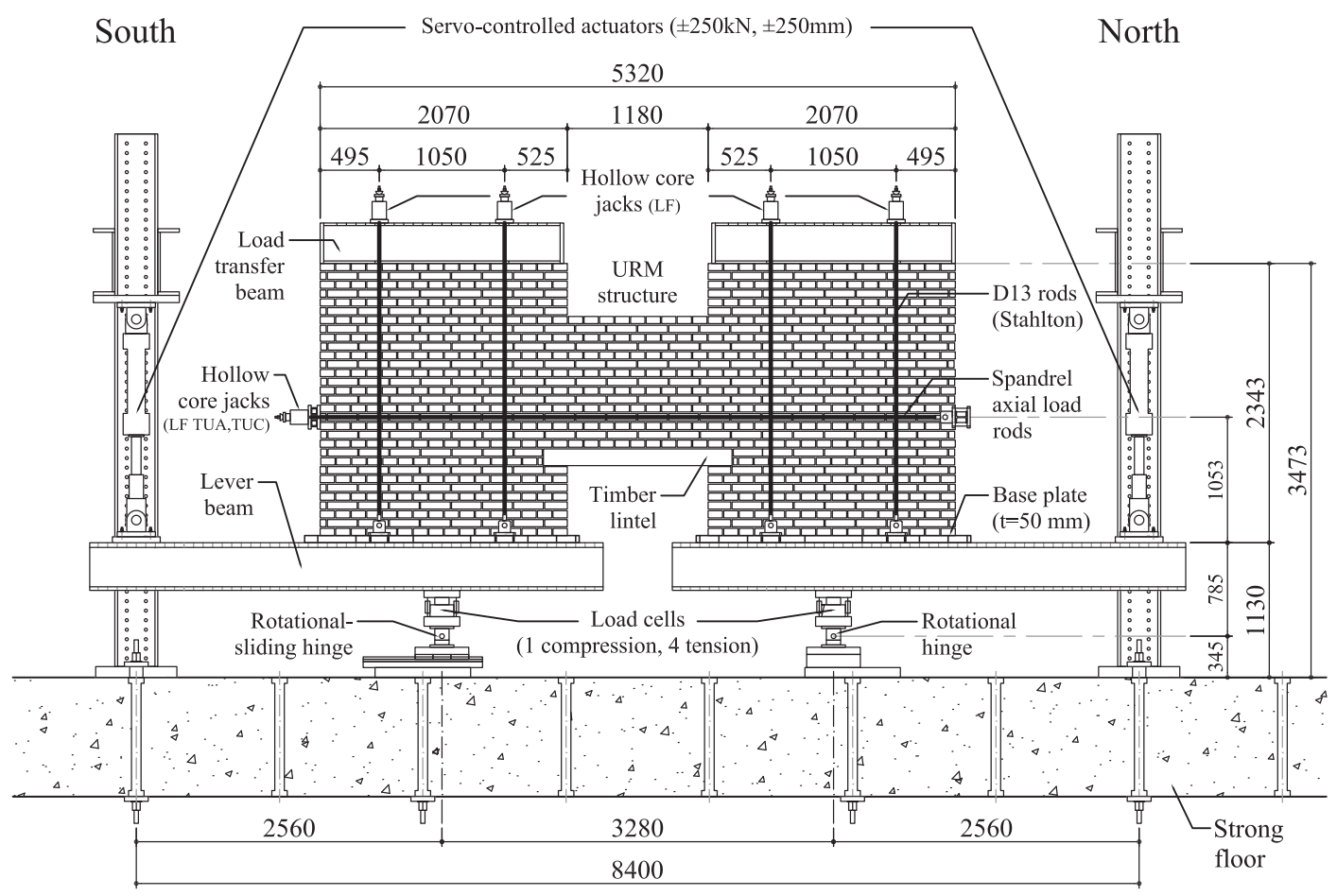

Fig. 14. Test setup for spandrel tests. Side restraint is not shown. All dimensions are in ( $\mathrm{mm})$. (LF = Hollow core jacks connected to load follower, which maintains constant oil pressure) [15]. 


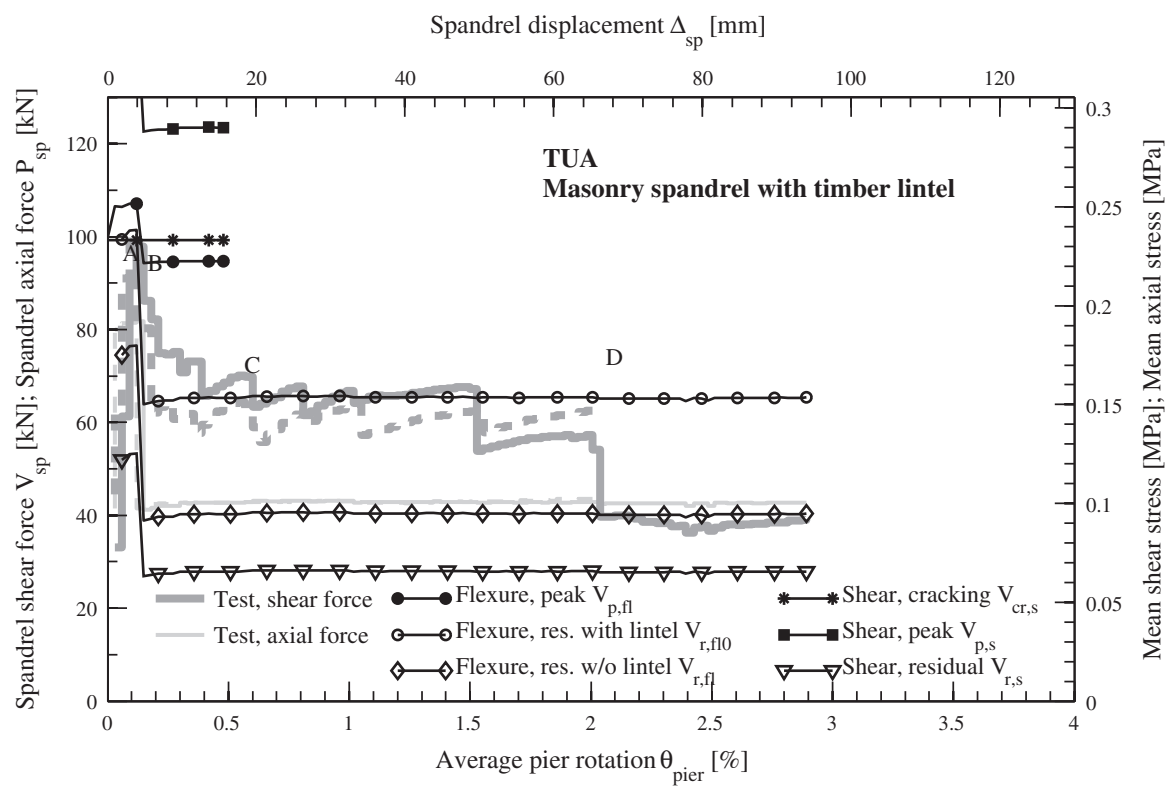

Fig. 15. TUA: Comparison of experimental and predicted shear strength values of the spandrel.

Table 4

TUA-TUD: observations during testing [15].

\begin{tabular}{|c|c|c|}
\hline Test unit & Point & Observation \\
\hline TUA & $\begin{array}{l}\text { A } \\
\text { B } \\
\text { C } \\
\text { D }\end{array}$ & $\begin{array}{l}\text { Flexural cracking for both loading directions }\left(\theta_{\text {pier }} \approx 0.1 \%\right) \\
\text { Shear cracking for the negative loading direction }\left(\theta_{\text {pier }} \approx 0.2 \%\right) \\
\text { Shear cracking for the positive loading direction }\left(\theta_{\text {pier }} \approx 0.6 \%\right) \\
\text { Failure of the lintel support for the positive loading direction }\left(\theta_{\text {pier }} \approx 2.0 \%\right)\end{array}$ \\
\hline TUB & $\begin{array}{l}\text { A } \\
\text { B } \\
\text { C }\end{array}$ & $\begin{array}{l}\text { Flexural cracking for both loading directions }\left(\theta_{\text {pier }} \approx 0.2 \%\right) \\
\text { Onset of degradation of one lintel support }\left(\theta_{\text {pier }} \approx 1.0 \%\right) \\
\left.\text { Lintel support fails; almost simultaneously rupture of one of the horizontal bars ( } \theta_{\text {pier }} \approx 1.5 \%\right)\end{array}$ \\
\hline TUC & $\begin{array}{l}\text { A } \\
\text { B } \\
\text { C } \\
\text { D } \\
\text { E } \\
\text { F }\end{array}$ & $\begin{array}{l}\text { First cracks in arch }\left(\theta_{\text {pier }} \approx 0.025 \% \text {, i.e., during the first load cycle) }\right. \\
\text { Crack, which started in arch, turns into a shear crack }\left(\theta_{\text {pier }} \approx 0.05 \%\right) \\
\text { Shear crack over entire height of spandrel for the positive loading direction }\left(\theta_{\text {pier }} \approx 0.1 \%\right) \\
\text { Shear crack over entire height of spandrel for the negative loading direction }\left(\theta_{\text {pier }} \approx 0.2 \%\right) \\
\text { Fracturing of outer bricks of arch due to large compressive stresses }\left(\theta_{\text {pier }} \approx 0.8 \%\right) \\
\text { Failure of arch }\left(\theta_{\text {pier }} \approx 1.9 \%\right)\end{array}$ \\
\hline TUD & $\begin{array}{l}\text { A } \\
\text { B } \\
\text { C } \\
\text { D } \\
\text { E } \\
\text { F }\end{array}$ & $\begin{array}{l}\text { First cracks in arch }\left(\theta_{\text {pier }} \approx 0.05 \%\right) \\
\text { Flexural crack pattern develops, no shear cracks }\left(\theta_{\text {pier }} \approx 0.2 \%\right) \\
\text { First shear cracks }\left(\theta_{\text {pier }} \approx 0.3 \%\right) \\
\text { Onset of damage to bricks forming arch }\left(\theta_{\text {pier }} \approx 0.8 \%\right) \\
\text { Shear cracks through arch, i.e., arch is heavily damaged }\left(\theta_{\text {pier }} \approx 2.0 \%\right) \\
\text { Final failure of arch }\left(\theta_{\text {pier }} \approx 3.0 \%\right)\end{array}$ \\
\hline
\end{tabular}

means of letters annotated in Table 4 important observations that were made during the test.

As the limit rotation that marks the transition between peak and residual strength is not yet known, the results for the equations of the cracking and peak strength are arbitrarily plotted up to a rotation of $0.5 \%$ whereas the results for the residual strength equations are plotted from $0.1 \%$ to the ultimate rotation. The two different plotting ranges were chosen to help the reader distinguish between the results of equations estimating the peak strength and the residual strength, respectively. To ease the readability of the graph, only the strength values computed with the axial force recorded for loading in the positive direction are plotted since for all tests the behaviour in the two loading directions was rather similar. The graph contains the peak and residual capacities for flexural and shear dominant behaviours; not included in the graphs is the strength associated with shear cracking through the bricks (Eq. (14)), as it led for all spandrels to a strength significantly higher than the strength associated with shear cracking through the joints (Eq. (13)).
TUA was tested with a constant axial force $P_{s p}$ in the spandrel, i.e., during the testing the load in the horizontal tie rods was kept constant by means of two hollow core cylinders. However, due to some problems with the test setup, the axial force $P_{s p}$ in the spandrel was reduced from $80 \mathrm{kN}$ to $40 \mathrm{kN}$ at a pier drift of approximately $0.2 \%$. The peak strength of TUA was obtained for an axial force of $80 \mathrm{kN}$. TUA developed first a flexural crack pattern, and at peak strength a shear crack developed. Fig. 15 shows that for TUA the computed peak flexural strength was $107 \mathrm{kN}$, which overestimates the observed strength by $7 \%$. At the peak strength, the computed shear cracking strength was reached, and shortly afterwards a shear crack formed (Point B). Note, that although the agreement between predicted and observed behaviour is in this case excellent, strictly speaking the equation for predicting the shear cracking strength is not applicable once the spandrel has developed a flexural crack pattern. The drop in residual flexural strength was caused by the reduced axial force in the spandrel. The residual experimental strength agrees very well with the predicted residual flexural strength before and after failure of the lin- 


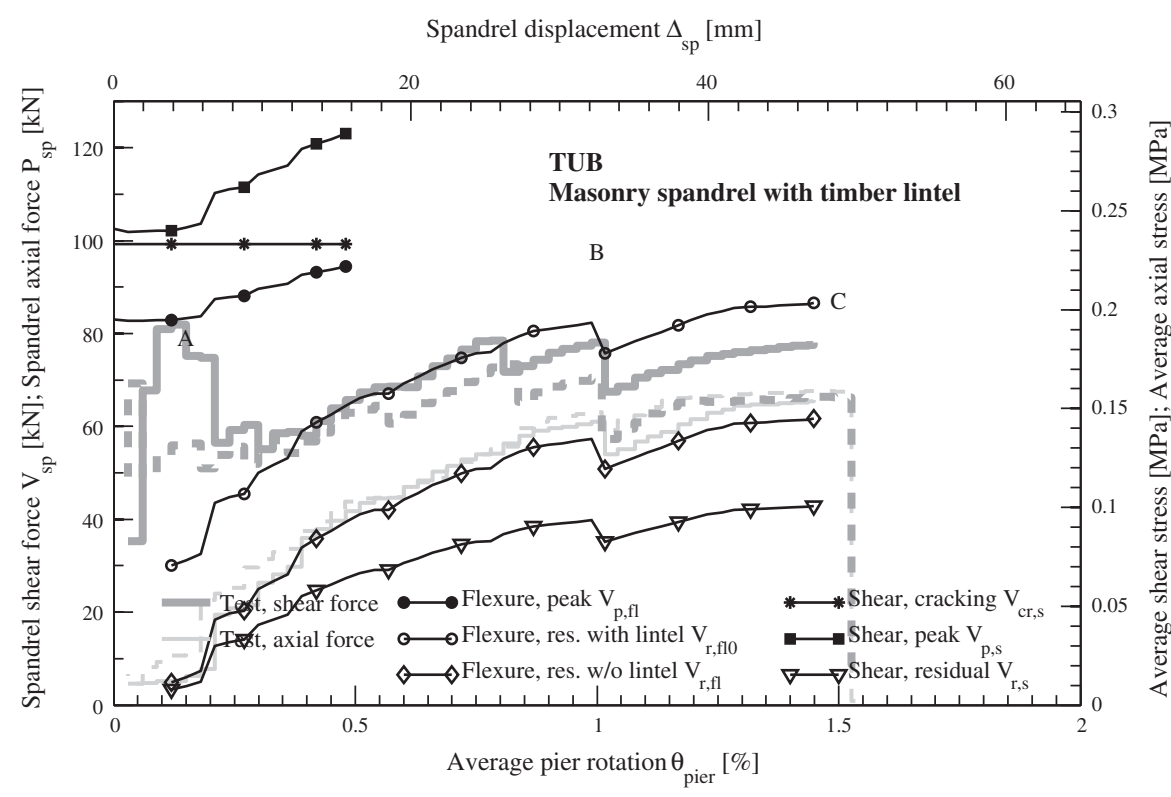

Fig. 16. TUB: Comparison of experimental and predicted shear strength values of the spandrel.

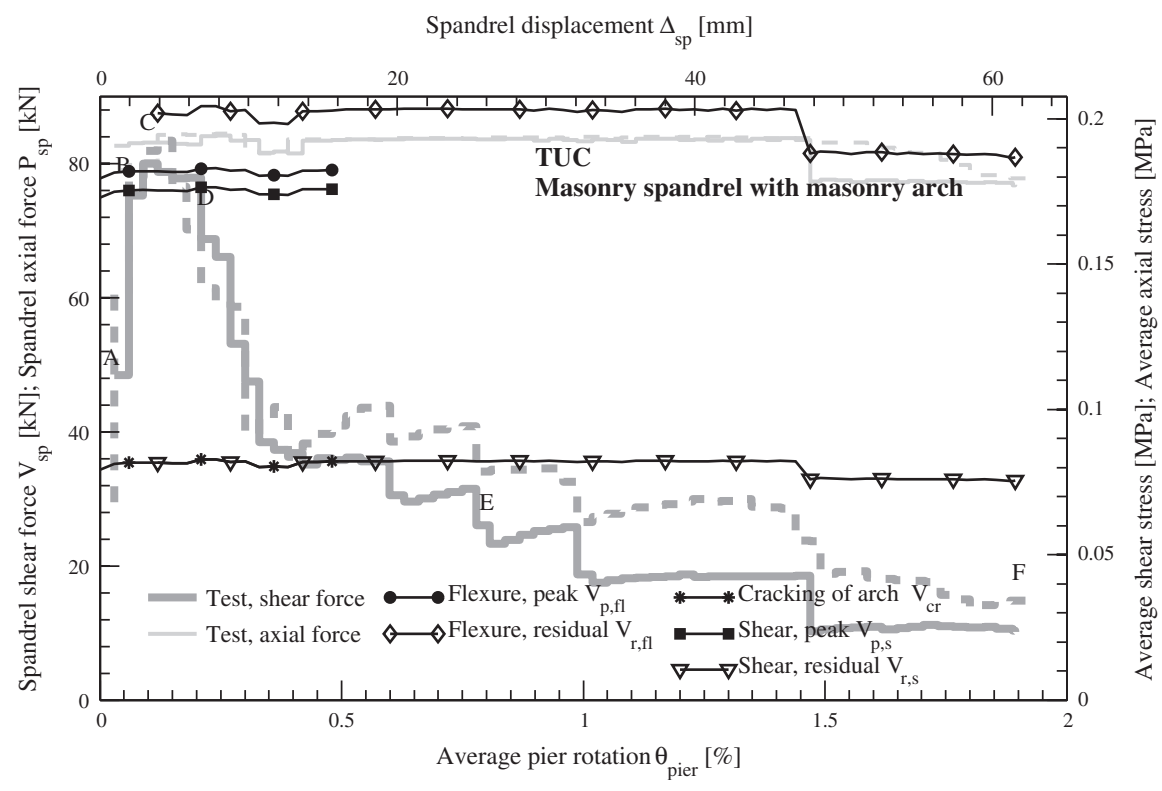

Fig. 17. TUC: Comparison of experimental and predicted shear strength values of the spandrel.

tel support (Point D). In the test, however, not a pure flexural mechanism but rather a mixed flexural-shear mechanism developed [15]. The residual shear strength attributed to the timber lintel underestimates the experimental residual strength of the spandrel underlining again that the proposed equations are limited to either a shear or a flexural mode but have limited capabilities in predicting the strength of spandrels developing flexural-shear mechanisms.

TUB was tested with an axial spandrel force that depended on the elongation of the spandrel. TUB developed a pure flexural mechanism. Fig. 16 shows that the peak flexural strength is well captured by the mechanical model. After the peak, the drop in strength is not immediate but occurs at a rotation of $\theta_{\text {pier }} \approx 0.2 \%$. In the following, the residual strength increases because the axial force in the spandrel increases. At $\theta_{\text {pier }} \approx 0.8 \%$ the experimental shear strength flattens out although the axial force in the spandrel continues to increase. Such behaviour marks the onset of the degradation of the residual mechanism (see Fig. 3), which is confirmed by the observed onset of failure of a lintel support at Point $\mathrm{B}$. Between Point $B$ and Point $C$, the experimental spandrel strength thus lies between the predicted values before and after failure of the lintel support. At Point $C$ the lintel support failed but one of the horizontal ties also ruptured. Hence, the axial force and therefore also the shear force in the spandrel suddenly dropped to zero.

\subsubsection{Masonry spandrels with shallow arches}

TUC was tested with a constant axial spandrel force of approximately $80 \mathrm{kN}$ (Fig. 17). The first crack that developed was within the shallow masonry arch and this crack developed during the first load cycle. After this first crack, the spandrel strength increased until at Point $C$ a shear cracked over the entire height of the spandrel formed. The peak shear strength is well predicted by the pro- 


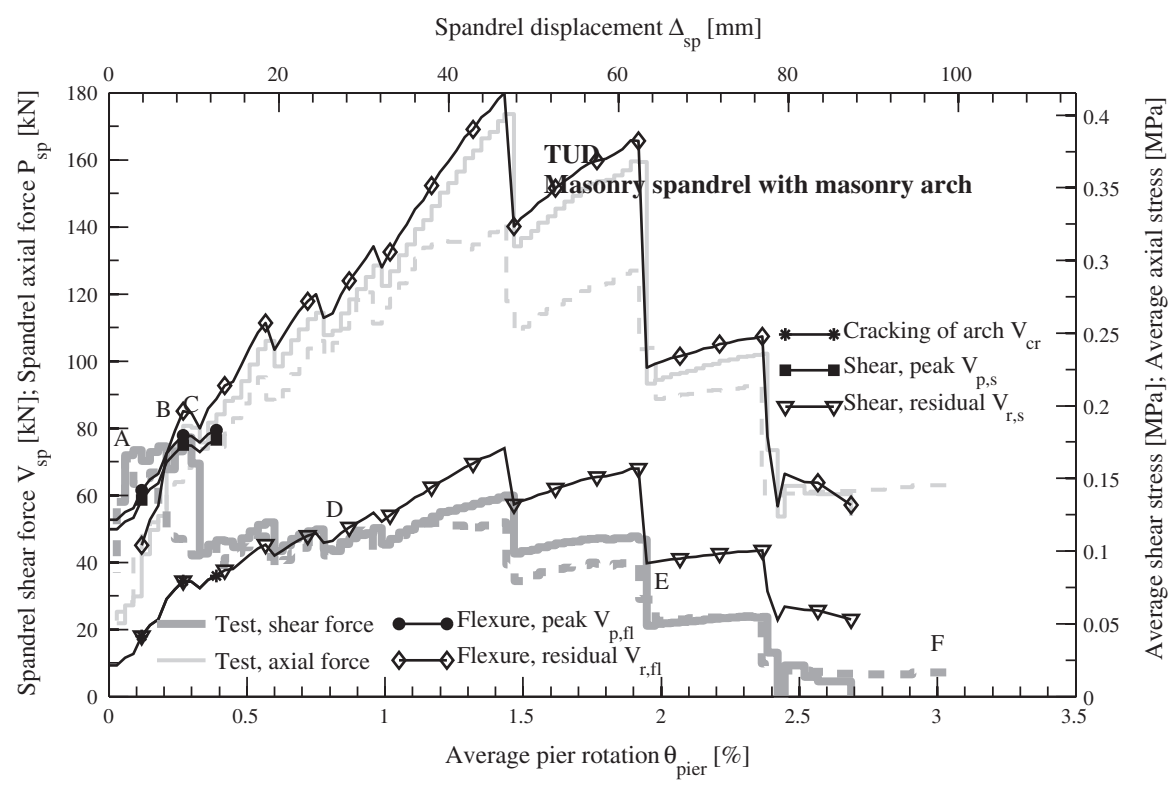

Fig. 18. TUD: Comparison of experimental and predicted shear strength values of the spandrel.

posed model. The predicted peak flexural strength lies only slightly above the predicted peak shear strength; the formation of some flexural cracks in the masonry spandrel was therefore expected and observed [15] although the flexural cracks did not dominate the behaviour of the spandrel element. After the formation of the shear cracks over the entire height of the spandrel, the spandrel strength dropped to its residual value. Note that the proposed model suggests that both the shear force marking the onset of cracking and the residual shear strength of a spandrel element with a masonry arch can be estimated as the shear force carried by the arch alone (Section 5.4). Fig. 17 shows that the proposed model also accurately captures the residual shear strength. This situation holds up to Point E, which marks the onset of degradation of the masonry arch. Damage and failure of the masonry arch was not considered in the proposed model; the behaviour beyond Point E could therefore not be captured.

TUD was tested with an axial force that depended on the axial elongation of the spandrel element (Table 3). In comparison to TUB, which was also tested with a variable axial force, the horizontal steel ties were much stiffer; i.e., for the same elongation, the increase in axial force was larger. As for TUC, the onset of cracking occurred in the arch at very small drift demands (Fig. 18, Point A). Due to the small axial force at the beginning of the test, these cracks in the arch did, however, not turn into shear cracks as for TUC, but rather into flexural cracks. Shortly after all flexural cracks had formed (Point B), the first shear cracks developed (Point C). This observation agrees well with the predicted peak flexural and shear resistance, which also lead to very similar values. The strong increase in axial force changes the behaviour from an originally flexure-dominant behaviour to a shear-dominant behaviour that controls the residual strength of the spandrel. As for TUC, the proposed model captures the residual shear strength well up to Point $\mathrm{D}$, which marks the onset of damage to the arch. Subsequently, the proposed model overestimates the shear strength of the spandrel element.

\section{Conclusions}

Realistic seismic assessments of URM buildings with timber floors need to account for the effect of the masonry spandrels on the global behaviour of the system. As a first step, the paper proposes simple mechanical models that describe in an approximate manner the force transfer mechanisms in the brick masonry spandrels at peak and residual strength. The input parameters for these models are the geometry of the spandrel element, material properties, which can be determined from standard material tests, and the axial force in the spandrel element.

The comparison of the predicted strength values to experimental results obtained from four quasi-static cyclic tests on masonry spandrels showed that the proposed models are able to predict the dominant mechanism and the corresponding peak and residual strength of the spandrel. The models were not derived for capturing mixed-mode behaviour including both shear and flexural cracks and for the two test units TUA and TUD exhibiting such behaviour, the difference between predicted and experimental behaviour was slightly larger. Future work should therefore include such mixed-mode behaviour and expand the models to masonry spandrels supported on different types of arches. In addition, the interaction of masonry spandrel and timber lintel or masonry spandrel and masonry arch should be investigated in greater detail in order to refine the proposed models. The results of this work have underlined that the strength of masonry spandrels is highly dependent on the axial force in the spandrels. Future research should therefore also develop models which allow estimating the axial force in the spandrel in URM wall configurations.

\section{Acknowledgments}

The review of the manuscript by Dr. Christoph Butenweg and one anonymous reviewer is gratefully acknowledged. I also wish to thank Prof. Hugo Bachmann, Dr. Alessandro Dazio and Sujith Mangalathu for their comments on the manuscript.

\section{References}

[1] Magenes G, Della Fontana A. Simplified non-linear seismic analysis of masonry buildings. In: Proceedings of the British Masonry Society, vol. 8; 1998. p. 1905.

[2] Magenes G. A method for pushover analysis in seismic assessment of masonry buildings. In: Proceedings of the 12th world conference on earthquake engineering, Auckland, New Zealand; 2000. 
[3] Galasco A, Lagomarsino S, Penna A. TREMURI program: seismic analyser of 3D masonry buildings. Theory and User Manual, University of Genova, Italy; 2002.

[4] Galasco A, Lagomarsino S, Penna A, Resemini S. Non-linear seismic analysis of masonry structures. In: Proceedings of the 13th word conference on earthquake engineering, Vancouver, Canada; 2004.

[5] Braga F, Liberatore D. A finite element for the analysis of the response of masonry buildings. In: Proceedings of the 5th North American masonry conference, Urbana, USA; 1990.

[6] Braga F, Liberatore D, Spera G. A computer program for the seismic analysis of complex masonry buildings. In: Proceedings of the 4th international symposium on computer methods in structural masonry, Pratolino, Italy; 1997.

[7] Cattari S, Lagomarsino S. A strength criterion for the flexural behavior of spandrels in un-reinforced masonry walls. In: Proceedings of the 14th world conference on earthquake engineering, Beijing, China; 2008.

[8] Milani G, Beyer K, Dazio A. Upper bound limit analysis of meso-mechanical spandrel models for the pushover analysis of 2D masonry frames. Eng Struct 2009;31(11):2696-710.

[9] Applied Technology Council. FEMA-306 - evaluation of earthquake damaged concrete and masonry wall buildings. Basic Procedures Manual, Washington, USA; 1998.

[10] O.P.C.M. 3274, 20/03/2003. First elements concerning general criteria for the seismic classification of the national territory and technical norms for structures in seismic zone [in Italian]. Primi elementi in materia di criteri generali per la classificazione sismica del territorio nazionale e di normative tecniche per le costruzioni in zona sismica.

[11] O.P.C.M. 3431/05, 09/05/2005. Further modifications and integrations on OPCM 3274/03" [in Italian]. Ulteriori modifiche ed integrazioni all' OPCM $3274 / 03$.

[12] Beyer K, Dazio A. Quasi-static monotonic and cyclic tests on composite spandrels. Earthquake Spectra, 2012.
[13] Dazio A, Beyer K. Experimental investigation of the effect of the longitudinal reinforcement content of ring beams on the cyclic behaviour of masonry spandrels. In: Proceedings of the11th North American masonry conference, Minneapolis, Minnesota, USA; 2011.

[14] Beyer K, Dazio A. Modelling of spandrel elements in URM structures with RC slabs or ring beams. In: Proceedings of the 11th North American masonry conference, Minneapolis, Minnesota, USA; 2011.

[15] Beyer K, Dazio A. Quasi-static cyclic tests on masonry spandrels. Earthquake Spectra, 2012.

[16] Beyer K, Abo-El-Ezz A, Dazio A. Quasi-static cyclic tests on different types of masonry spandrels. IBK report no. 327, Institute of Structural Engineering, ETH Zürich, Switzerland; 2010.

[17] Magenes G, Calvi GM. In-plane seismic response of brick masonry walls. Earthquake Eng Struct Dyn 1997;26:1091-112.

[18] Frumento S, Magenes G, Morandi P, Calvi GM. Interpretation of experimental shear tests on clay brick masonry walls and evaluation of q-factors for seismic design. Report, Eucentre. Pavia, Italy: IUSS Press; 2009.

[19] CEN. Eurocode 8: design of structures for earthquake resistance - Part 3: General rules, seismic actions and rules for buildings. Design Code EN 1998-3, European Committee for Standardisation, Brussels, Belgium; 2005.

[20] Cervenka V. Atena - computer program for nonlinear finite element analysis of reinforced concrete structures. Theory and user manual, Prague, Czech Republic; 2007.

[21] Rots JG, Lourenço PB. Fracture simulations of masonry using non-linear interface elements. In: Proceedings of the 6th North American masonry conference, Philadelphia, USA; 1993.

[22] Heyman J. The stone skeleton. Int J Solids Struct 1966;2:249-79.

[23] Ochsendorf JA. The masonry arch on spreading supports. Struct Eng 2006;85(2):29-35. 